\title{
La influencia del monte arbolado en las empresas transformadoras de la madera en Galicia
}

\section{The influence of forestland in wood processing companies in Galicia}

\author{
Ángel Miramontes Carballada* y M. ${ }^{a}$ Pilar Alonso Logroño**
}

\section{INTRODUCCIÓN Y OBJETIVOS}

Los recursos forestales procedentes del monte han sido tradicionalmente un elemento de gran importancia para el desarrollo socioeconómico de muchos territorios, e incluso en las sociedades avanzadas continúan siéndolo, adquiriendo un valor creciente por su carácter de recursos escasos. Esto es así, tanto por su aportación a la mejora de la calidad de vida, a la estabilidad de los ecosistemas naturales, a la generación de actividades de ocio, como por la producción de materias primas renovables con posibilidades de alto valor añadido, como la madera (Montiel, 2003; Piussi y Farrell, 2000). Asimismo se debe considerar que el monte tiene la capacidad de contribuir al desarrollo rural, promoviendo un aprovechamiento integral y equilibrado de los recursos que genera, y que ayudan a mitigar el proceso de despoblación (Orduño y Zamora, 2001). Aunque para todo esto lo que necesita el monte es una buena ordenación y gestión, que garantice la calidad ambiental, la diversidad del paisaje y la conservación de la flora y la fauna, sin olvidar la satisfacción de demandas sociales y económicas (Balboa, 1990; Rico, 1993; Miramontes, 2010; FAO, 2012).

\footnotetext{
* IDEGA (Instituto Universitario de Estudios e Desenvolvemento de Galicia), Universidade de Santiago de Compostela (angelmiramontes@gmail.com).

** Departamento de Geografía y Sociología, Universitat de Lleida (p.alonso@geosoc.udl.cat).
} 
En este contexto son muchos los territorios que han desarrollado su potencial económico apoyándose en los recursos naturales extraídos del monte y que todavía hoy continúan haciéndolo (Ministerio de Medio Ambiente, 2002; Fischer et al., 2010). Una de las actividades tradicionales favorecidas por la presencia forestal arbolada, han sido las relacionadas con la transformación de sus recursos arbóreos, ubicándose en el entorno del lugar de extracción diversas actividades dedicadas a la transformación de madera. Es cierto que los avances relacionados, sobre todo, con los medios de transporte permite localizaciones más flexibles de estas actividades, pero cuestiones como el «saber hacer» o la propia cercanía de la materia prima, siguen dando prioridad a algunos territorios para la localización de determinadas actividades de transformación de la madera, allí donde se desarrolla el monte forestal arbolado.

Para demostrar las afirmaciones anteriores, en este trabajo se presenta el ejemplo de un territorio, Galicia, donde tanto en el pasado como en el presente se ha producido una fuerte vinculación entre la localización de las masas arboladas de los montes y de las empresas transformadoras de madera.

Es necesario señalar como primer rasgo importante que a lo largo de la historia el monte gallego siempre ha mantenido una fuerte significación en el desarrollo social, medioambiental, económico y cultural de su región. Sin embargo, esta importancia ha estado condicionada por una serie de actuaciones, principalmente de origen humano, que han tenido como resultado la conformación del monte actual de Galicia y también de las actividades de transformación que en paralelo se han desarrollado vinculadas con él (Rodríguez, 1989; Guitián, 1995; Valdés y Gil, 2001).

Los principales cambios que ha presentado el monte gallego a lo largo del tiempo fueron provocados por diferentes procesos acaecidos, principalmente, en el medio rural gallego (crisis demográfica, crisis del sector primario, etc.), entre los que cabe destacar la relevancia que ha jugado la búsqueda de la rentabilidad económica de la principal materia prima obtenida en los montes gallegos, la madera. Precisamente en este trabajo se pretende mostrar la relación existente entre la situación actual de las masas forestales arboladas y la industria transformadora de la madera. El resultado del proceso indica que a lo largo de la historia forestal de Galicia se manifiestan fuertes carencias en cuanto a la gestión y a la planificación, especialmente en lo referente a la utilización de técnicas sociales y culturales con objetivos económicos (Miramontes, 2010). 


\section{Hitos PRINCIPALES DE LA TRAYECTORIA SOCIOECONÓMiCA DEL MONTE GALLEGO}

Dentro de la trayectoria histórica del sector forestal gallego se sucedieron una serie de hitos que han originado que a lo largo del tiempo el monte gallego se fuera transformando hasta llegar a la situación actual, muy distante del pasado, al igual que las actividades relacionadas con él. Aunque no es el objetivo central de este trabajo apuntaremos algunos de esos hitos, que han sido estudiados en profundidad por autores como Xesús Balboa López ${ }^{1}$; Carlos Manuel Valdés y Luis Gil Sánchez²; o en la multitud de estudios de Luis Ceballos sobre cuestiones forestales en diferentes escalas y ámbitos de toda España.

Al remontarnos a la antigüedad comprobamos como los montes de la región, al igual que en otros territorios, siempre tuvieron una relación muy directa con las diferentes actividades que iban proliferando en la economía gallega: la aparición de la agricultura, la ganadería o actividades como la cerámica, la minería o la metalurgia tuvieron una fuerte relación con el sector forestal como ha sido muy bien estudiada por historiadores de la economía (Balboa, 1990; Prada, 1991; Valdés y Gil, 2001 o Carmona y Nadal, 2005). Fue sobre todo a partir de la Edad Media, cuando el monte se convierte en un agente fundamental para el desarrollo socioeconómico y se comienza a detectar la presión en los mismos de la actividad agrícola y de actividades artesanales como las herrerías o la construcción naval.

Esta presión en la Edad Moderna desembocó ya en una deforestación, provocada por el incremento demográfico y el mayor desarrollo de la actividad agrícola. Además se comienzan a detectar las dificultades de relación entre los usos madereros del monte, la actividad agrícola-ganadera y diferentes actividades artesanales como las curtidurías o la construcción naval. En ese momento la práctica totalidad de la demanda de materia prima surgida de la construcción naval, a escala nacional, fue suministrada por los montes gallegos. Salvo ciertas partes de los barcos como los mástiles que al tener que ser de gran porte y perfectamente rectos se importaban del Báltico (Ferreira, 1988 y Guitián, 1995). Igualmente en esta etapa, se dieron una serie de hitos desarrollados desde el gobierno de España (Ordenanza de Montes, 1748) donde el territorio gallego fue uno de los protagonistas principales (Urteaga, 1987; Guitián, 1995; Valdés y Gil, 2001). Como consecuencia de este proceso se empieza a favorecer la conversión de antiguos robledales en pinares, porque se trataba de una

\footnotetext{
${ }^{1}$ Balboa López, X. (1990): O monte en Galicia. Vigo, Editorial Xerais, 359 pp.

2 Valdés, C. M. y Gil, L. (2001): La transformación histórica del paisaje forestal en Galicia. Madrid, Ministerio de Medio Ambiente, 159 pp.
} 
especie bien adaptada al terreno (según los intereses económicos de esa época) y de rápido crecimiento (Guitián, 1995; Rey, 1995; Valdés y Gil, 2001).

A lo largo del siglo XIX, destaca la crisis del castaño frente al auge progresivo del pino. En gran medida motivado por una serie de factores como: el elevado consumo de la madera de castaño, la pérdida de «valor» de la castaña en la alimentación humana y del ganado y, sobre todo, a la enfermedad de la «tinta» que desde finales del siglo XIX viene acompañando a esta especie en Galicia (Fernández, 1984). A la vez que el castaño perdía superficie el pino la ganaba, tanto de modo espontáneo como artificial (Bouhier, 1979; Valdés y Gil, 2005). Además en esta etapa influyó de un modo muy marcado la desamortización y la significación que siempre tuvieron en la sociedad gallega los montes vecinales en «man común» (MVMC), lo que explica en gran medida la estructura actual del monte en Galicia (Artiaga, 1991; Cruz, 1994).

En el siglo XIX se produjo otro hito que siguió transformando las superficies de los montes gallegos, como fue la intensificación productiva a través de la conformación de policultivo de subsistencia. La gran explotación del terreno, obteniendo más de una cosecha al año necesitaba una fertilización constante y abundante que sólo era posible con la integración agrícola-ganadera y la dedicación a tojales de grandes superficies, proceso que resto importantes superficies forestales (Balboa, 1990; Prada, 1991; Valdés y Gil, 2001; Miramontes, 2010).

En el siglo xx aparecen otros elementos, que se mantienen en la actualidad, y continúan modificando la caracterización de los montes gallegos como son las repoblaciones y los incendios forestales. En cuanto a las repoblaciones destacar que el territorio gallego, desde inicios del siglo $\mathrm{xx}$, fue objetivo de iniciativas tanto públicas como privadas centradas en la producción de un tipo de madera muy específica y con un mercado muy limitado. Los diferentes procesos de repoblación que se fueron sucediendo a lo largo de la historia forestal de Galicia se caracterizarán por la colonización del pino y del eucalipto, especialmente por toda la franja litoral de Galicia y, por la continuidad en la pérdida progresiva de especies como el castaño y el roble. Salvo pequeñas excepciones, las repoblaciones siempre se caracterizaron por perseguir unos fines económicos rápidos y concretos, por lo que no se utilizaron las especies más cercanas al clímax forestal de las escalas sucesionales espontáneas como robles, castaños o árboles de ribera. Ni una tipología de madera apta para todas las actividades o subsectores transformadores de madera. Aunque bien es cierto que esta transformación de los montes favoreció, entre otras, a la actividad de aserraderos para la preparación de cajas para el pescado o fruta (Rico, 1993, 1995 y 1997). 
En cuanto a los incendios, a lo largo de la historia reciente del monte gallego, se han convertido en el principal problema del sector forestal, con una serie de causas y consecuencias que van más allá de la protección del monte. La gravedad de los incendios forestales dentro de Galicia es que se mantienen en el tiempo, a pesar de la sensibilización que parece existir en la sociedad gallega sobre este tema y, lo que es más grave, la mayoría son intencionados. A modo de ejemplo entre 1995 a 2005 el 85\% de los incendios forestales en Galicia fueron intencionados, mientras que la media española de incendios forestales intencionados no llegó al 40\% o, en el 2010 casi el 30\% de la superficie arbolada quemada de España se produjo en Galicia (Miramontes, 2010 y Ministerio de Medio Ambiente y Medio Rural y Marino, 2011).

Por tanto, el monte gallego es hoy reflejo de éstas y de otras acciones que han terminado configurando el espacio forestal arbolado cuyas características se examinan a continuación, para seguidamente observar la posible relación que tiene la presencia de determinadas masas forestales con la existencia de una actividad de transformación de la madera en Galicia.

2. Situación De los RECURSOS FORESTALES, EL MONTE, Y SU TRANSFORMACión A ESCALA GLOBAL Y LOCAL

Uno de los factores clásicos para la localización de las empresas de transformación ha sido la existencia de recursos naturales que sirvieran de materia prima, elemento relevante cuando el coste del transporte era elevado y los medios y la red insuficientes. Hoy, estas dificultades han sido superadas (Salom y Albertos, 2009; Méndez et al., 2004; Albertos J. M. et al., 2004; Alonso, J. L.; Aparicio, L. J. y Sánchez, J. L., 2004; Salom, J., 2003; Caravaca. I., González, G., Méndez, R. y Silva, R. 2002; Méndez y Alonso; 2002; Méndez, R. y Alonso, J. L., 2000; Méndez, R., 2001, 2000, 1998, 1997, 1994; Méndez y Caravaca, 1996; Precedo y Villarino, 1991), pero todavía se pueden encontrar ejemplos que reflejan la relación entre la presencia de empresas transformadoras y la de materias primas. En unos casos la relación se muestra porque se sigue utilizando la materia prima en empresas ubicadas próximas a ella; en otras ocasiones porque se ha conservado el «saber hacer» en la transformación de los recursos naturales, lo que ha permitido mantener esta actividad aunque la materia prima ya no sea autóctona. Un ejemplo de estas situaciones puede encontrarse en los recursos forestales arbolados. En concreto, es lo que ocurre en Galicia, una región con importantes recursos forestales y con un buen «saber hacer» en el tratamiento de la madera, pero con particularidades de comportamiento, como se examina en este trabajo. 
La madera es un recurso natural importante que se asociada a muchas actividades económicas que forman los eslabones de la denominada «cadena de la madera». Desde la producción en el monte de la madera, hasta su transformación por parte de las diversas empresas, se generan actividades muy relevantes para la organización social y económica de los espacios afectados con su presencia. Por ello, es importante observar las relaciones que surgen dentro de la industria de la madera, donde se engloba tanto el monte que produce la materia prima, como las distintas actividades relacionadas con su transformación. Es necesario insistir que este trabajo se centra solo en esa concepción del recurso forestal como recurso fabril, ya que una buena parte de la caracterización de las masas forestales puede estar relacionada con la transformación que se puede hacer de ellas, aunque como se ha mencionado son más las concepciones a valorar de las masas forestales.

\subsection{Recursos forestales y su consumo}

La madera es necesaria como material de construcción, para la fabricación de pasta y papel, como combustible e insumo para la producción de energía, y para una amplia gama de usos más. Esto sin duda es un aspecto que viene preocupando sobre todo a los países productores, ya que exige una continua producción del mismo si se quiere seguir contando con él. Se trata de un bien que hay que cuidar y ordenar para lograr cubrir las necesidades, de ahí que desde ámbitos diversos se intente poner freno a su disminución y sobre todo que se camine hacía un análisis y un control de los diferentes tipos de masas forestales.

Las pérdidas de superficie forestal se explican tanto por catástrofes naturales (incendios, inundaciones, etc.), como por el consumo de masas forestales arboladas para su transformación, aspecto este último importante en todo el mundo. Hay que recordar que la madera es, detrás del petróleo, el recurso natural más consumido (FAO, 2010a).

Según el informe de la FAO sobre la evaluación de los recursos forestales mundiales (2010), el proceso de deforestación, aunque ha disminuido su ritmo, sigue aumentando (figura 1). Si en la década de 1990 se perdieron 16 millones de hectáreas anuales, entre 2000 y 2010 han desaparecido 13 millones de hectáreas anuales. Las mayores mermas se produjeron en Sudamérica, (siendo Brasil el país que más disminución sigue experimentando) y en África (donde el fenómeno adquiere su mayor relevancia en Nigeria, el Congo o Tanzania).

Junto a esto destacar como el área forestal europea continúa expandiéndose, aunque a un ritmo más lento que en la década de 1990. Europa es una 
de las áreas donde la superficie forestal aumenta cada año, con una media de 740.000 ha, siendo precisamente España el país que encabeza este incremento, con 4,4 millones de hectáreas más en los últimos 15 años, según el informe de la Situación de los Bosques en el Mundo 2009 (FAO, 2010b). Pero en el caso de las áreas más desarrolladas no sólo hay que considerar la materia prima sino también su aprovechamiento y las relaciones con el resto de la «cadena de la madera».

En el ranking europeo, España, con 27,6 millones de hectáreas, es el segundo país por superficie forestal total (incluyendo la arbolada y la desarbolada), detrás de Suecia, y con casi el doble de superficie que Francia y el triple que Alemania. Si se observa sólo la superficie forestal arbolada España se sitúa en tercer lugar, detrás de Suecia y Finlandia (FAO, 2010b).

De acuerdo con la información tomada del último Anuario de Estadística Forestal de España (MMA, 2008), la superficie forestal del país es de 27.664.674 ha, lo que supone el $51 \%$ del territorio nacional y de las que 18.267.750 ha son arboladas y 9.396.924 ha desarboladas.

De todo este espacio, destaca el territorio gallego, donde el uso mayoritario de su suelo es el forestal; 1.921.250 ha de los casi 3 millones de hectáreas que tiene esta Comunidad Autónoma. En cuanto a la superficie forestal arbolada Galicia tiene algo menos de 1.400 .000 hectáreas, lo que representa el $47 \%$ de

FIGURA 1

TENDENCIAS EN LA EXTENSIÓN DE LOS BOSQUES 1990-2010 (1.000 HA)

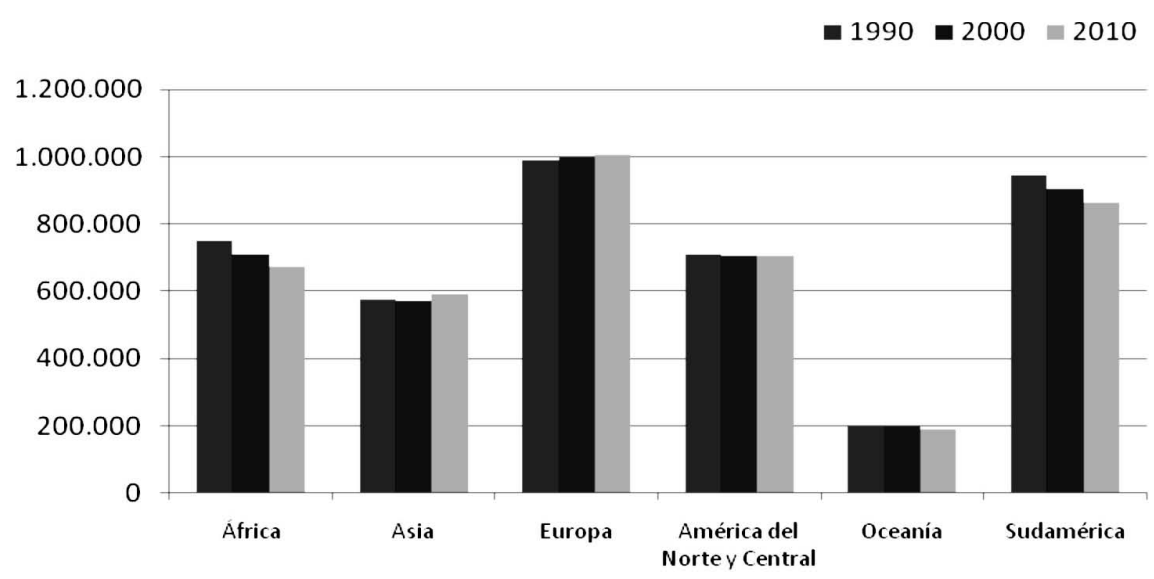

Fuente: elaboración propia a partir de datos de Evaluación de los Recursos Forestales Mundiales 2010 (FAO, 2010a). 
su territorio, el 10\% de la superficie forestal arbolada española y el 2,5\% de la europea. Datos que sin duda confirman que Galicia es una de las más importantes potencias forestales a escala española y también europea. Esta superficie, a pesar de los incendios que la afectan, sigue aumentado, a través de políticas de reforestación. Desde 1993 en Galicia se han puesto en marcha importantes programas de reforestación de sus montes, lo que ha ofrecido cifras muy significativas de hectáreas repobladas, destacando el año 1998, con más de 13.400 ha repobladas, y el año 2006, superando las 13.500 ha (Miramontes, 2010).

Pero junto a la ocupación del suelo por superficie forestal, la otra variable importante a considerar es la producción de madera y su utilización. Precisamente en este aspecto destaca de nuevo el territorio gallego. Galicia es una de las comunidades autónomas españolas de las que se extrae más materia prima del uso forestal. De los montes gallegos sale la mitad de la madera que se produce en España. En concreto, según cifras del III Inventario Forestal de España, en Galicia se produce un volumen de tala de madera industrial de aproximadamente $7 \mathrm{~mm}^{3} /$ año, además de $1,5 \mathrm{~mm}^{3} /$ año de leña, lo que en conjunto supone algo más del $50 \%$ de la madera que se tala anualmente en España y del orden del 4,5\% de la europea. En estas condiciones Galicia se convierte en el «almacén forestal» de España (Miramontes, 2010).

\subsection{Transformación de la madera}

El panorama descrito sobre la ocupación forestal y la extracción de madera, no describe la localización de las áreas transformadoras de la madera, y por tanto de los consumos de esta materia prima. Es bien conocido que áreas como África o Latinoamérica, son espacios de grandes recursos forestales que han sido esquilmados por países transformadores. Pero hoy, los avances acometidos en los medios de transporte y en la logística de los intercambios no permiten identificar el mapa de producción de madera con el de su transformación, complicando la explicación del reparto.

Las actividades fabriles asociadas a la madera buscan factores de localización en los que la ubicación de la materia prima ha ido perdiendo su importancia. A esto hay que añadir que antiguas áreas productoras de madera a veces también se asocian a la transformación de la misma, pero no tiene porque utilizar la madera que sus propios montes producen. Mostrar estos procesos es el objetivo central de este trabajo, para lo que Galicia es un buen ejemplo, por la abundancia del recurso forestal y la importancia que adquieren las actividades asociadas a la transformación de la madera, pero utilizando en numerosas ocasiones madera de otras procedencias. 
A pesar de que las cifras planteadas en el apartado 2.1. muestran el importante papel que juega Galicia en el sector forestal español, tanto en la ocupación del suelo como en extracción de madera, cuando se observa su significación en el proceso transformador, hay que decir que el sector gallego está marcado por las contradicciones. Como se ha comentado, Galicia produce casi la mitad de la madera que se obtiene en España, encabezando además las exportaciones de madera a varios países como Portugal, Italia o Marruecos (Galiforest, 2010). Pero a la vez Galicia, es la tercera comunidad importadora de madera, con 337 millones de euros por detrás de Valencia (367) y Cataluña (342) (Galiforest, 2010). Por lo que Galicia que además de abastecerse de madera de sus montes, exporta parte de su producción y recurre al mercado exterior para comprar una tipología de madera que no encuentra en su territorio.

Esta situación muestra el importante desequilibrio entre la producción de madera en gran cantidad y la necesidad de importar un volumen considerable de madera debido a que en la mayoría del territorio español no se diseñaron unas plantaciones, ni planes de ordenación forestal acordes con las necesidades del mercado interno de todas las fases de transformación, algo que también le ocurre a Galicia (figura 2).

\section{FIGURA 2}

SALDO COMERCIAL DE LA TIPOLOGÍA DE LA PRODUCCIÓN DE MADERA EN ESPAÑA. DIFERENCIA ENTRE EXPORTACIÓN E IMPORTACIÓN. $\left(1.000 \mathrm{M}^{3}\right.$ Y $1.000 \mathrm{~T}$ PASTA Y PAPEL)

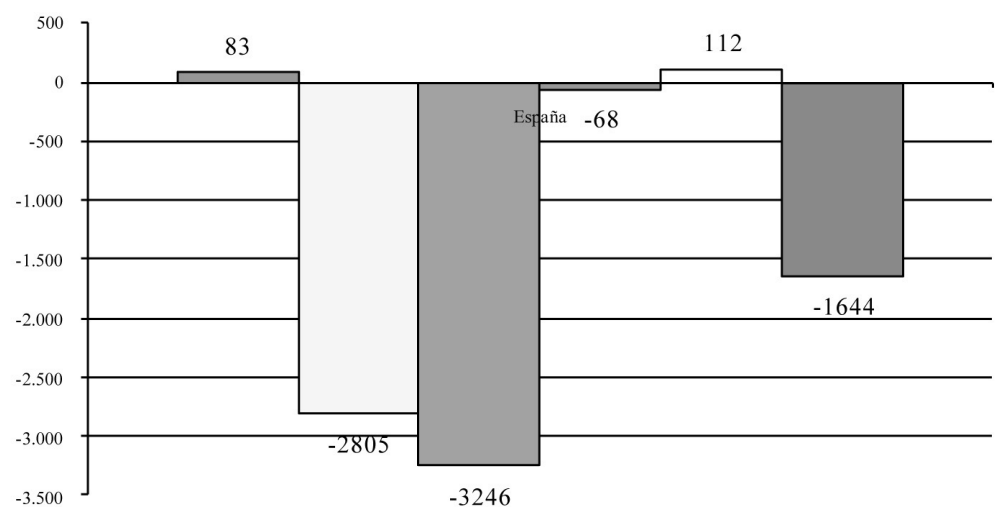

$\square_{\text {Leña }} \square_{\text {Madera en rollo }} \square_{\text {Madera aserrada }} \square_{\text {Tableros }} \square_{\text {Pasta }} \square_{\text {Papel }}$

Fuente: elaboración propia a partir de datos de Situación de los Bosques del Mundo 2009 (FAO, 2010b). 
Observando la situación de producción de madera en España los valores más importantes, se centran en la primera transformación de la madera (aserrado, chapa, tableros y pasta de papel) produciendo una gran cantidad de madera en rollo y de primera transformación para la industria, pero empieza a perder significación en cuanto se le comienza a dar más transformación a la madera (figura 3). Situación que refleja también lo que acontece en Galicia en donde se centralizó toda la producción en un tipo de madera muy concreto que, principalmente, se destina a la trituración (eucalipto) y, aserrado, chapa y tableros (pino), pero de un modo deficitario e insuficiente. Pues estas chapas y tableros no siempre acaban en las carpinterías o fábricas de muebles gallegas.

A pesar de la situación planteada sobre la necesidad de importar, los valores de la industria transformadora de la madera en España siguen siendo importantes. El sector aglutina a más de 200.000 empleados y tiene una cifra de negocio de casi 25.000 millones de euros (INE, 2010). Dentro de estos importantes valores destaca Galicia, que es la Comunidad que aporta el mayor porcentaje de facturación dentro del sector, con un 19\%, seguida de cerca por la C. Valenciana con un $16 \%$ o Cataluña con un 15\%, pero las demás regiones no llegan al 9\%. Lo que nos indica la significación que tiene esta actividad en la estructura económica de Galicia (INE, 2010).

FIGURA 3

VALORES DE LA TIPOLOGÍA DE LA PRODUCCIÓN DE MADERA EN ESPAÑA (1.000 $\mathrm{M}^{3}$ Y $1.000 \mathrm{~T}$ PASTA Y PAPEL)

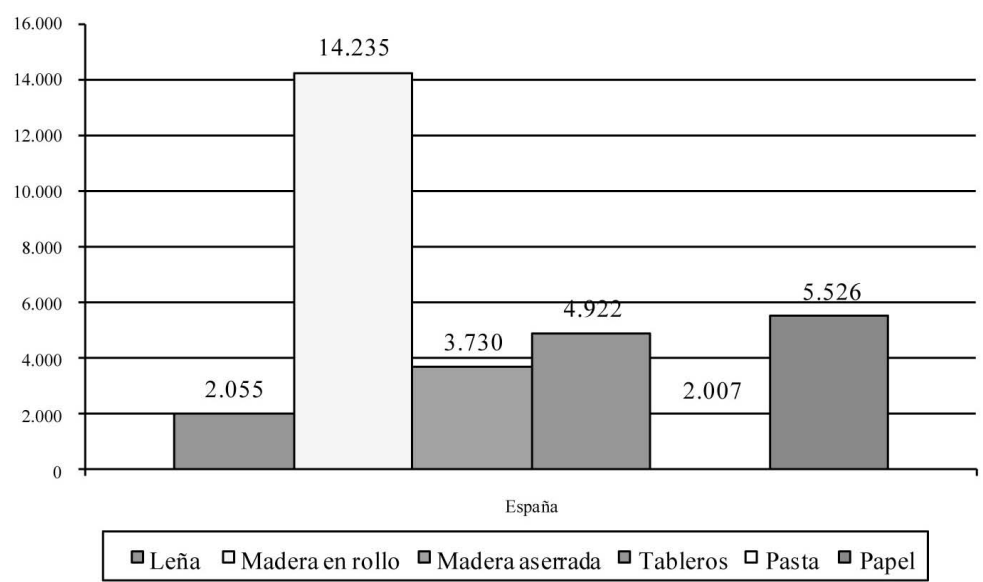

Fuente: elaboración propia a partir de datos de Situación de los Bosques del Mundo 2009 (FAO, 2010b). 
Los datos anteriores confirman que Galicia, es el «almacén forestal» de España, pero también que es un territorio donde la industria transformadora de la madera tiene una gran significación dentro del país, aunque con peculiaridades.

En los últimos años las más de 2.500 empresas que componen esta actividad industrial en Galicia superaron los 2.000 millones de euros de facturación, representaron más del 3,5\% del PIB de Galicia y tuvieron un volumen de empleados directos de 20.000 personas (Miramontes, 2010). Pero para comprender mejor su caracterización es necesario aludir al tipo de actividad que realizan. Así se pueden dividir entre las que se dedican a la $1^{a}$ transformación sobre la madera, y las que realizan una $2^{\mathrm{a}}$ transformación sobre los productos derivados del primer grupo. Dentro de la $1^{a}$ transformación se encuentran las de aserrado, chapas y tableros e industrias de producción de pasta de papel, que en total aglutinan más de 300 empresas, que facturan más de 1.200 millones de euros y tienen más de 6.000 trabajadores. Mientras que la $2^{a}$ transformación está formada por las carpinterías y las fábricas de muebles que reúnen 2.200 empresas con una facturación de 700 millones de euros y un volumen de empleo de 12.000 trabajadores (a lo largo de este artículo volveremos a estos valores generales).

Dentro de las actividades que se incluyen en la primera transformación, sin lugar a dudas, Galicia destaca en el conjunto español, pues además de representar la mitad de la madera en rollo que se prepara en España, tiene unos valores por encima del 30\% en la producción de tableros, madera aserrada y producción de pasta de papel. Hay que apuntar que la mayoría de estas producciones salen al exterior de la comunidad gallega, por lo que los beneficios que se pueden obtener con la segunda transformación salen en su mayoría fuera. Además se detecta un fuerte desequilibrio con la representatividad de la segunda transformación de la madera, donde Galicia sólo alcanza el 8\% de toda España (figura 4).

Las preguntas surgen de inmediato ¿Por qué Galicia es el territorio que más madera corta y posee la industria de la primera transformación más potente de España y, sin embargo su madera y sus productos no sirven para la segunda transformación, a pesar de localizarse en ella un número muy alto de este tipo de actividades?. Precisamente este tipo de cuestiones, son a las que se intenta dar respuesta en este trabajo.

A lo largo de los años la política forestal gallega se preocupó por orientar la productividad de sus montes hacia un tipo de madera de rápido crecimiento, principalmente pino y eucalipto, para solventar la demanda de madera de empresas como ENCE (empresa productora de pasta de papel instalada en Gali- 
FIGURA 4
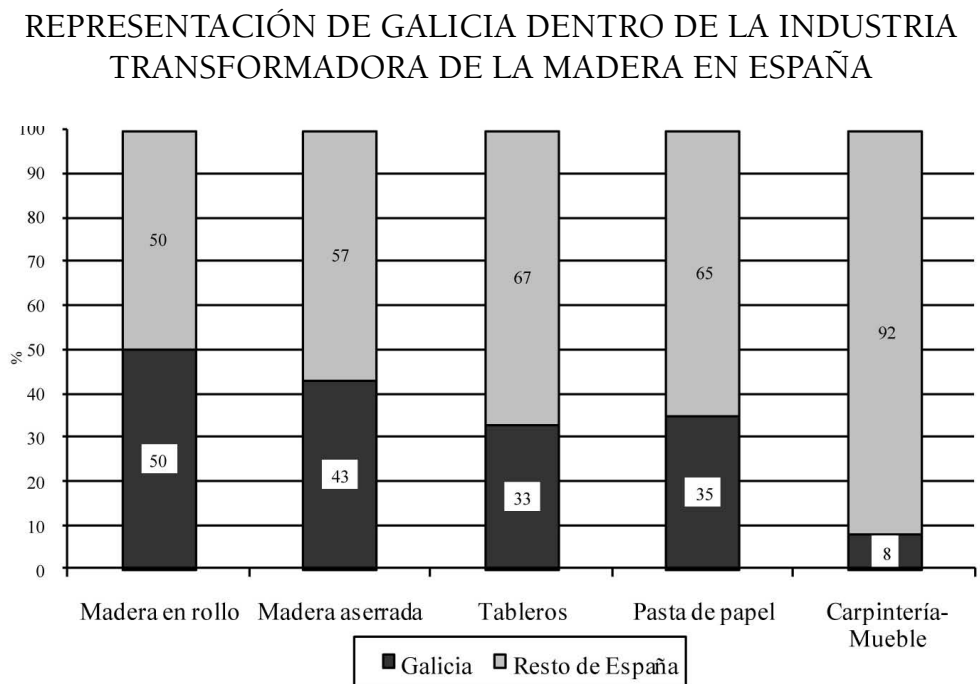

Fuente: elaboración propia a partir de datos de Industria Forestal en Galicia 2007-2008 (Asociación MonteIndustria et al., 2007-2008).

cia desde mediados del siglo xx). Pero además de centrarse en estas especies, el problema se agudizó al limitar la capacidad de crecimiento (ejemplares muy juntos, plantaciones intensivas) y acortar al máximo los turnos de corta (produciendo ejemplares de diámetros muy reducidos), por lo que la madera que se obtiene tan solo sirve para la industria de la primera transformación, principalmente para la producción de pasta de papel, aserraderos o productores de tableros de escasa calidad. Con ese tipo de materia prima se elaboran unos productos que no satisfacen las demandas de la industria de la segunda transformación presentes en Galicia (carpinterías especializadas o fábricas de muebles), pues los tableros y chapas producidos en Galicia no tienen las características necesarias para ser utilizadas en todas las fases de producción de las fábricas de muebles gallegas.

Los datos anteriores confirman que la madera es un recurso presente en Galicia y que también hay industrias transformadoras como se examina más adelante, pero donde es necesario abordar el análisis detallado tanto de la caracterización de la materia prima como de las empresas de transformación, para observar como se pierden parte de las potencialidades que tendría el sector forestal gallego con una mejor relación entre los eslabones de la cadena de la madera. 


\section{LA DiSTRIBUCIÓN TERRITORIAL DE LAS MASAS ARBÓREAS EN GALICIA}

En este apartado se presenta la distribución de las masas arbóreas del monte gallego en la actualidad, que como se viene insistiendo son consecuencia tanto de las características naturales de este territorio, como de la acción del hombre y de sus necesidades. La finalidad principal de realizar esta revisión, es comprobar cómo la presencia o la ausencia de determinadas especies, así como sus características, no influyeron ni influyen en el desarrollo cotidiano de la actividad de las empresas de la industria transformadora de la madera de Galicia, pero si a la inversa.

Para el análisis de las masas forestales arboladas se ha trabajado con el «Mapa de coberturas e usos do solo de Galicia» elaborado por el SITGA (Sistema Territorial de Galicia) actualizado en el 2005 (se trata de la base de Galicia para el 4 Inventario Forestal Nacional).

Sobre esta fuente se planteó una reclasificación de la leyenda y se realizaron algunas transformaciones para alcanzar nuestro objetivo, el análisis de los espacios forestales arbolados y no del resto de usos. Según los datos trabajados las zonas forestales representan el $58,56 \%$ del territorio gallego, y si solo se incluyen las zonas forestales que están arboladas y consolidadas suponen el $32 \%$. Un monte no tiene porqué ser arbolado, pero dadas las características que se buscan en este trabajo se representan y analizan las zonas que tienen masas arbóreas, sus especies y su distribución.

En cuanto a la distribución territorial de las superficies forestales arboladas (figura 5) se comprueba como dibuja una «corona» que envuelve la zona central de Galicia.

A lo largo de toda la franja del litoral atlántica predominan montes mixtos (principalmente de pino y eucalipto). En la franja del litoral cantábrica es donde se encuentran los montes de eucaliptos como especie mayoritaria. A lo largo de las sierras orientales, las áreas de montaña de Galicia, es donde se asientan las masas de caducifolias, que a medida que se alejan de estas zonas incrementan su mezcla con otras especies. En estas sierras orientales encontramos los mejores ejemplos de montes de castaños y robles, especies predominantes en otras épocas en Galicia (Miramontes, 2010).

En cuanto a la representatividad de cada uno de los grupos de especies arbóreas, la primera conclusión que se puede extraer es que más del 17\% de la superficie total de Galicia está ocupada por masas arbóreas mixtas, que superan el $55 \%$ del total de la superficie forestal arbórea. Otro valor a destacar es el $27 \%$ que representan las especies de frondosas. Dentro de este porcentaje la especie que tiene mayor peso es el eucalipto, mientras que otras 
FIGURA 5

DISTRIBUCIÓN DE LAS MASAS FORESTALES ARBÓREAS DE GALICIA

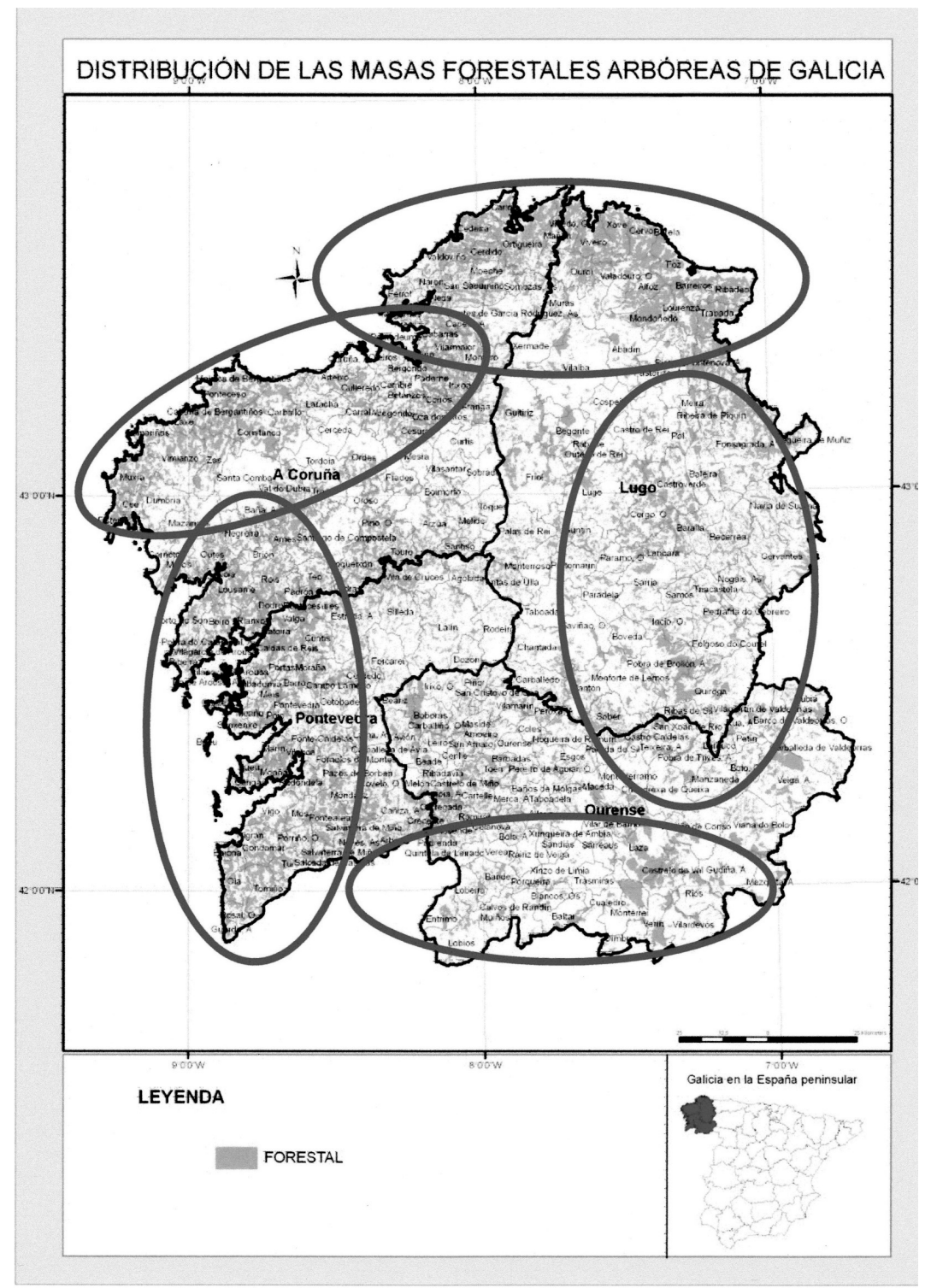

Fuente: elaboración propia a partir del Mapa de coberturas e usos do solo (SITGA, 2005).

Estudios Geográficos, Vol. LXXIV, 274, pp. 153-191, enero-junio 2013

ISSN: 0014-1496, eISSN: 1988-8546, doi: 10.3989/estgeogr.201306 
frondosas como los robles o los castaños tienen menor representatividad. Otra de las especies importantes son las coníferas que representan el 18\% de la superficie arbolada de Galicia y, casi en su totalidad se trata de pino (figura 6).

Al observar las masas forestales por tipos, y relacionarlas con la localización de las empresas se comprueba como realmente la mayoría de empresas transformadoras de la madera se encuentran próximas a áreas arbóreas mixtas. Esto indica que estas empresas utilizan mayoritariamente el pino y el eucalipto para su proceso productivo, y además esto se relaciona con las empresas de la primera transformación. Frente a esto en las áreas en las que predominan las frondosas el número de empresas es menor, exceptuando el norte de la provincia de Lugo en donde se encuentra uno de los eucaliptales más importantes de la Europa Atlántica. Las proximidades de las empresas transformadoras de madera más importantes como FINSA S.A. en Santiago de Compostela o ENCE-Pontevedra el predominio de masas mixtas de pino y eucalipto es muy importante, lo que demuestra como la proximidad de la materia prima en algunas actividades sigue siendo un factor de localización.

La distribución territorial de los tres grandes grupos de especies arbóreas a las que se hace referencia: frondosas, coníferas y masas mixta (ver figura 7), es

FIGURA 6

PORCENTAJES DE FRONDOSAS, CONÍFERAS Y MIXTAS DENTRO DE LA SUPERFICIE TOTAL Y DE LA FORESTAL DE GALICIA

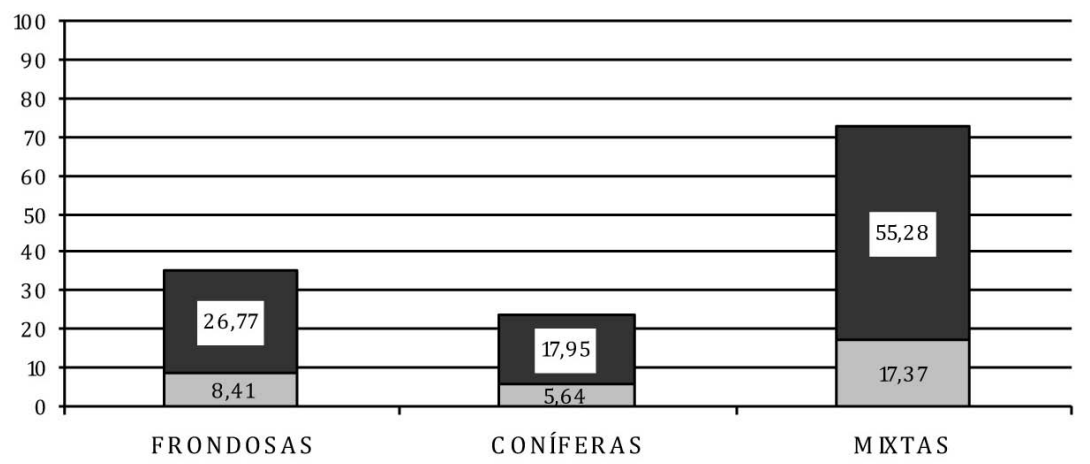

Galicia $\square$ Forestal

Fuente: elaboración propia a partir del Mapa de coberturas e usos do solo (SITGA, 2005). 
FIGURA 7

DISTRIBUCIÓN DE FRONDOSAS, CONÍFERAS Y MASAS MIXTAS EN GALICIA

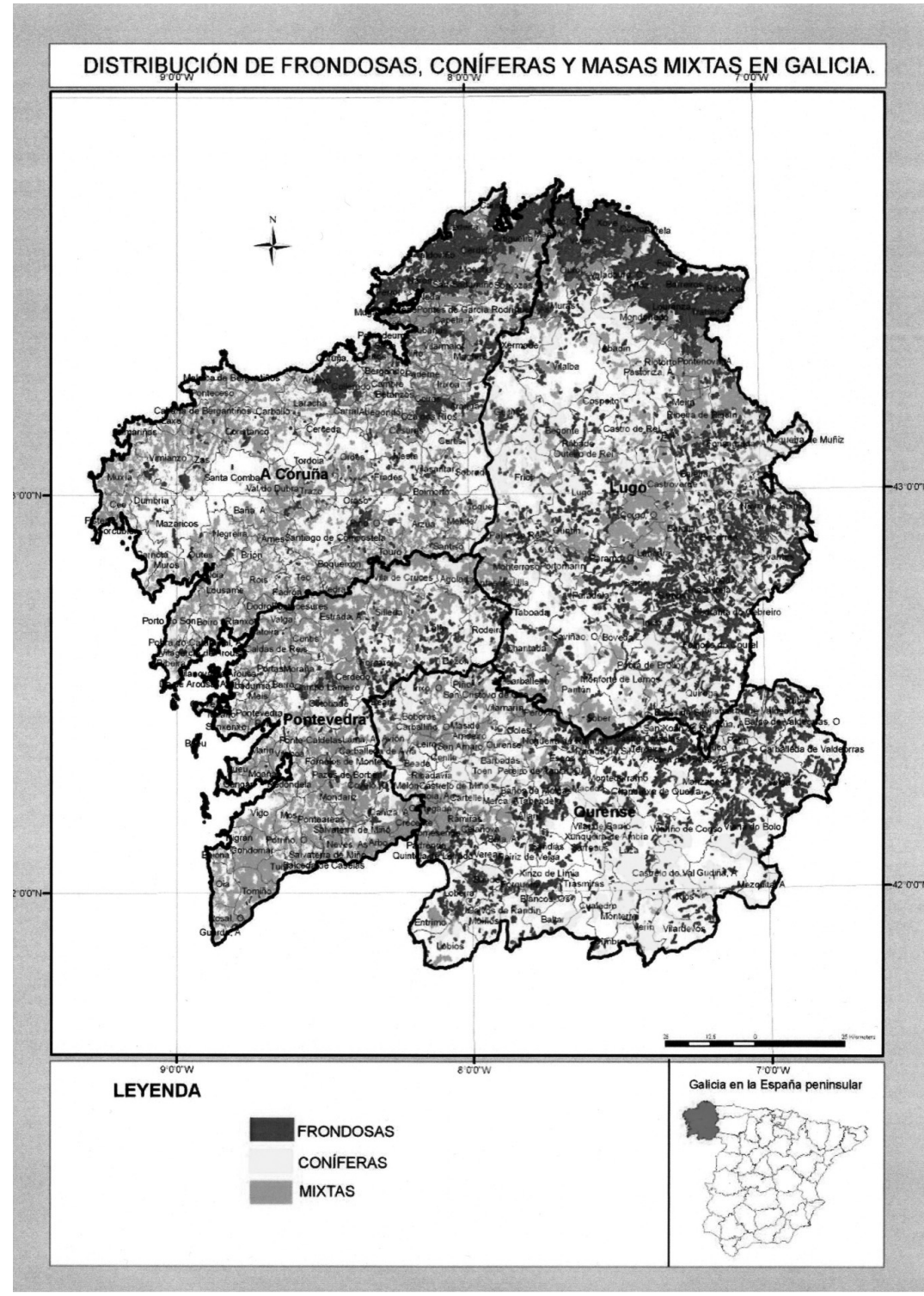

Fuente: elaboración propia a partir del Mapa de coberturas e usos do solo (SITGA, 2005).

Estudios Geográficos, Vol. LXXIV, 274, pp. 153-191, enero-junio 2013

ISSN: 0014-1496, eISSN: 1988-8546, doi: 10.3989/estgeogr.201306 
consecuencia de múltiples factores que, se relacionan, como se viene repitiendo, tanto con los condicionantes del medio natural como con la acción humana.

Así, dentro de las frondosas vemos como la mayor densidad se localiza al norte de la provincia de Lugo, concretamente en la denominada «Mariña Lucense» y al norte de la provincia de A Coruña. Se trata de uno de los territorios donde los procesos de repoblación con eucaliptos fueron más pronunciados. Otra zona donde predominan las frondosas es a lo largo de las sierras orientales, aunque su densidad es menor y ya no se tratan de eucaliptos sino de zonas con robles, castaños y otras caducifolias como las especies de ribera, sauces, fresnos, abedules, etc. Las razones naturales de esta distribución de las frondosas se centran principalmente en que los montes de caducifolias, se asientan en zonas de montaña, en las que la acción del hombre ha sido menos pronunciada, tanto desde el punto de vista productivo (agricultura y ganadería), como de creación de infraestructuras (suelo industrial, carreteras, embalses, etc.). Mientras que las razones artificiales (repoblaciones, abandono de suelos agrícolas, etc.) son las que permitieron que el eucalipto abarque, con una elevada intensidad, toda la zona norte de las provincias de Lugo y A Coruña. A su vez las condiciones naturales de la orografía, clima y suelos de estas zonas «ayudaron» a la implantación de esta especie (figura 8).

Dentro de las especies de frondosas no sólo hay diferencias desde el punto de vista del territorio donde se localizan, sino también desde el punto de vista industrial. Los eucaliptos son una especie de repoblación plantada en Galicia con la finalidad de producir materia prima para las empresas productoras de pasta de papel, mientras que los robles y los castaños no tienen la posibilidad de ser aprovechados hoy desde el punto de vista industrial, puesto que poco a poco fueron cortados y los que quedaban se les dejaba sin cuidados por parte del hombre (ejemplares localizados en zonas de difícil acceso, troncos muy ramificados, torcidos,...).

Próximas a estas últimas frondosas es donde se localizan las superficies de coníferas, principalmente pino, aunque tienen una mayor dispersión. De todos modos existen zonas como la central y sur de la provincia de Ourense donde es la especie predominante. La mayoría de estos pinares son aptos para la industria transformadora, pero como veremos tienen unas características que limitan sus usos, reduciéndose en exclusividad a las empresas que pertenecen a la primera transformación (aserraderos y productores de chapas y tableros). Es una especie con una significativa presencia dentro de determinadas áreas de monte mixto, pero existen bastantes montes que están formados en exclusividad por pinos (figura 9). 
FIGURA 8

DISTRIBUCIÓN DE FRONDOSAS EN GALICIA (CADUCIFOLIAS, CASTAÑO Y EUCALIPTO)

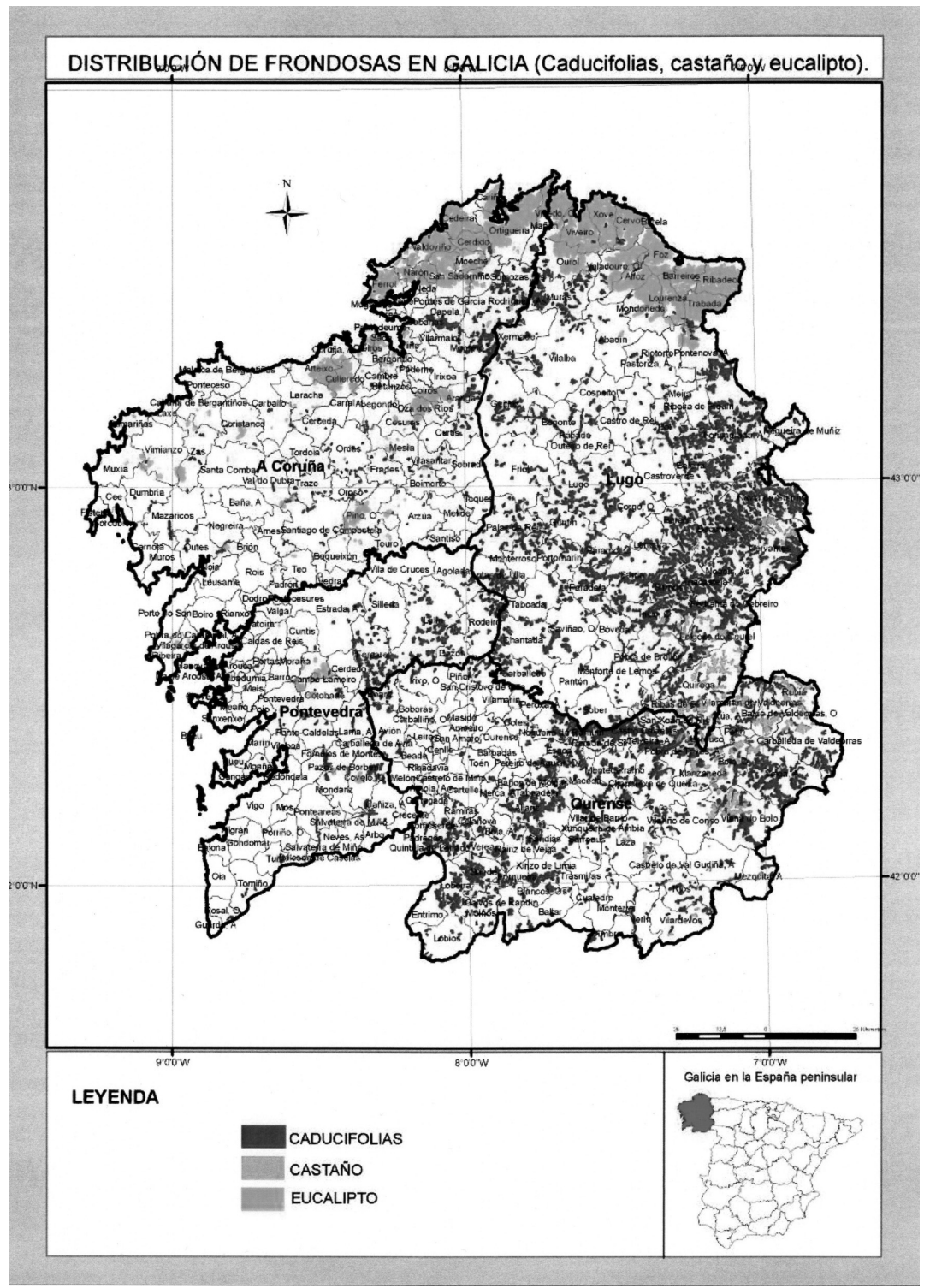

Fuente: elaboración propia a partir del Mapa de coberturas e usos do solo (SITGA, 2005).

Estudios Geográficos, Vol. LXXIV, 274, pp. 153-191, enero-junio 2013

ISSN: 0014-1496, eISSN: 1988-8546, doi: 10.3989/estgeogr.201306 


\section{FIGURA 9}

DISTRIBUCIÓN TERRITORIAL DE LAS CONÍFERAS EN GALICIA (PINO)

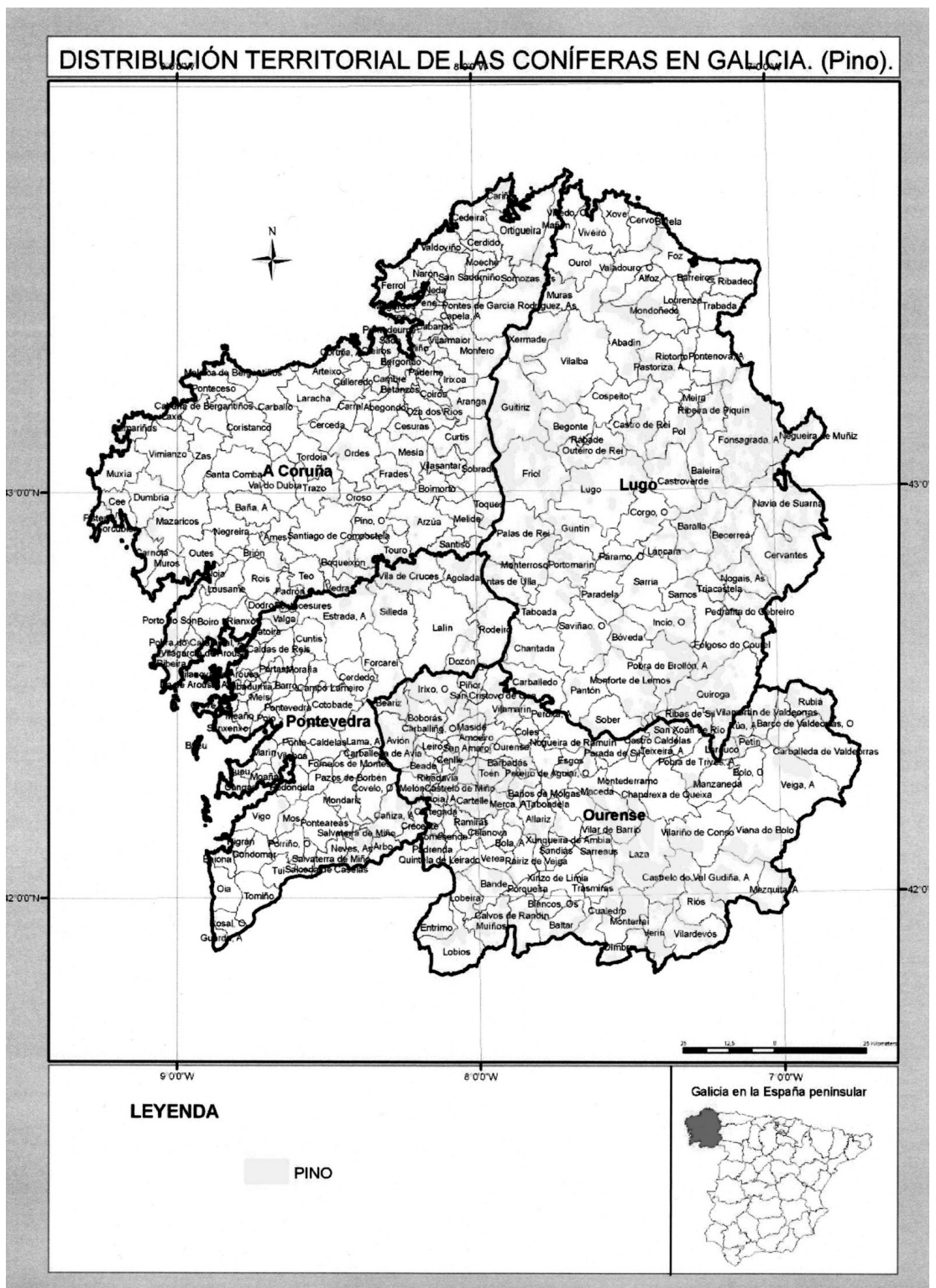

Fuente: elaboración propia a partir del Mapa de coberturas e usos do solo (SITGA, 2005).

Estudios Geográficos, Vol. LXXIV, 274, pp. 153-191, enero-junio 2013 ISSN: 0014-1496, eISSN: 1988-8546, doi: 10.3989/estgeogr.201306 
Su perfecta adaptación a las características naturales del territorio, así como por el hecho de ser en la actualidad y en el pasado, la especie por excelencia de los diferentes planes de repoblación forestal han provocado que el $18 \%$ de la superficie forestal esté ocupada hoy por pinos, sin contar la superficie que ocupan en los montes mixtos. A su vez tenemos que destacar que mientras los pinos de los montes mixtos se encuentran en la franja atlántica de Galicia, los pinares más importantes se asientan a lo largo de gran parte de las provincias orientales (Lugo y Ourense). Desde el punto de vista industrial, indicar que a pesar de la gran cantidad de pino que se produce en los montes gallegos, muchas empresas se ven obligadas a importar madera de pino de otros territorios, porque el gallego, entre otros motivos, es pino para ser tratado a turnos cortos y no alcanza la tipología y la calidad de madera que necesitan las carpinterías o fábricas de muebles autóctonas.

Dentro del grupo de los montes mixtos también destaca el pino, pues además de convivir con el eucalipto, ocupa el 22\% de los montes mixtos en unión con diferentes caducifolias.

En cuanto a su distribución territorial, la principal característica que presentan los bosques mixtos es el orden que siguen desde las zonas de litoral hacia el interior (figura 10). En las zonas más próximas al mar las especies predominantes son el pino y el eucalipto, que aprovecharon perfectamente las condiciones naturales de este territorio. A esto hay que añadir su mayor capacidad de adaptación. Los propietarios sabían de la demanda de madera de estas especies en Galicia desde mediados del siglo xx, por la instalación de una empresa productora de pasta de papel en la ciudad de Pontevedra, que consume grandes cantidades de madera de eucalipto joven.

En una segunda línea, podríamos hablar del prelitoral e incluso un poco más hacia el interior, es donde surgen otro conjunto de especies que forman los montes de arbolado mixto. Un clima un poco más frío y seco, así como una orografía más accidentada y el ser un territorio donde el sector primario aun mantiene significación, permite que a los eucaliptos y pinos se unan ejemplares de caducifolias. Dentro de estas caducifolias hay bastante heterogeneidad, que abarca desde robles, castaños a especies de ribera.

Cuanto más nos alejamos del mar y nos acercamos a las zonas interiores de Galicia, se comprueba como se reduce progresivamente la presencia del eucalipto. Por lo que los montes mixtos del interior de Galicia se caracterizan por el predominio de pinos y otras especies de caducifolias.

Por último, antes de acabar el análisis del reparto de masas arbóreas en Galicia, por la gran extensión que ocupa y por la significación en la organización forestal de la región se incorpora una referencia más particular sobre el euca- 
FIGURA 10

DISTRIBUCIÓN DE MASAS MIXTAS EN GALICIA (CADUCIFOLIAS Y PINO; EUCALIPTO Y PINO; EUCALIPTO, PINO Y CADUFOLIAS)

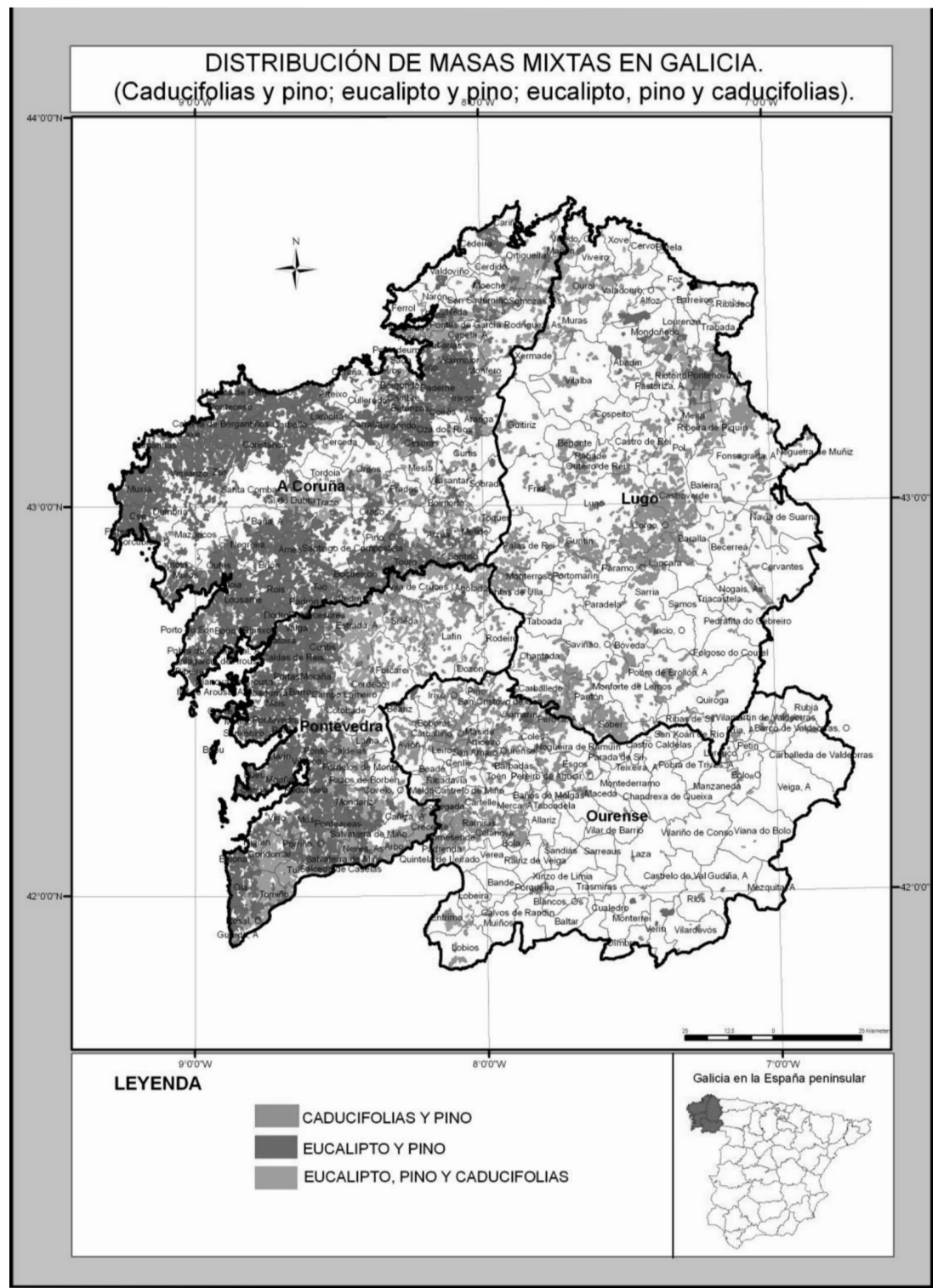

Fuente: elaboración propia a partir del Mapa de coberturas e usos do solo (SITGA, 2005). 
lipto. Se considera importante exponer como llegó esta especie a Galicia, la significación que adquirió dentro de los montes y un breve razonamiento sobre el valor o no de esta especie. Hay que tener en cuenta que desde diferentes foros esta especie es defendida a ultranza o bien es rechazada.

El origen del eucalipto, su hábitat natural, es Australia, concretamente en el sudeste en los estados de Victoria, Nueva Gales del Sur y Tasmania. Muchos botánicos e historiadores afirman que su colonización de nuevos territorios se apoyó en que se trata de una especie de rápido crecimiento y que llega a alcanzar unos portes impresionantes. De hecho, esta última característica fue la que animó, a mediados del siglo XIx, al gallego Fray Rosendo Salvado (monje benedictino) a enviar unas semillas desde Australia con destino a diferentes jardines y «pazos» gallegos. Pero de esta finalidad ornamental, pasado un siglo aproximadamente, a mediados del siglo xx el eucalipto se convirtió en la especie promovida por las empresas productoras de papel. Las óptimas aptitudes de este árbol para la producción de papel se desarrollaron en la primera mitad del siglo xx en Portugal y tras los buenos resultados productivos se trasladó a Galicia.

La gran cantidad de materia prima que consumen las empresas productoras de pasta de papel, es por tanto una de las causas principales de la proliferación de plantaciones de eucalipto destinadas a abastecer a estas empresas. La presencia de un comprador de la madera, la planta de ENCE en Pontevedra, las políticas de repoblación, el éxodo rural, la gran fragmentación del territorio en pequeñas parcelas y múltiples propietarios que lo ven como una mera inversión con la finalidad de obtener el mayor beneficio del modo más rápido, o la buena adaptación del eucalipto a las peculiaridades del medio natural gallego con un rápido crecimiento, han provocado que en la actualidad el eucalipto esté presente en cerca de 512.828 hectáreas, el $18 \%$ de la superficie total de Galicia. Concretamente cerca de 113.000 hectáreas están ocupadas por masas puras de eucalipto, en 281.000 se combina con el pino y en 120.000 se mezcla con pino y con ejemplares de caducifolias. El eucalipto ocupa toda la franja litoral y prelitoral de Galicia, incluso se adentra muchos kilómetros hacia zonas interiores (figura 11).

De todos modos destaca una zona ya citada sobre las demás, toda la «Mariña Lucense» donde además de tener las masas más densas y puras de eucalipto, también tiene algunos de los ejemplares más grandes y antiguos de Galicia. En algunos casos se tratan de ejemplares de más de 120 años y que alcanzan alturas de 70 o 80 metros. A lo largo de toda la franja atlántica su presencia también es muy importante, pero en este caso ya es más difícil encontrarlo solo, sino que forma masas arbóreas mixtas en unión con ejem- 


\section{FIGURA 11}

DISTRIBUCIÓN TERRITORIAL DE EUCALIPTO EN GALICIA (EUCALIPTO, EUCALIPTO Y PINO, EUCALIPTO, PINO Y CADUCIFOLIAS)

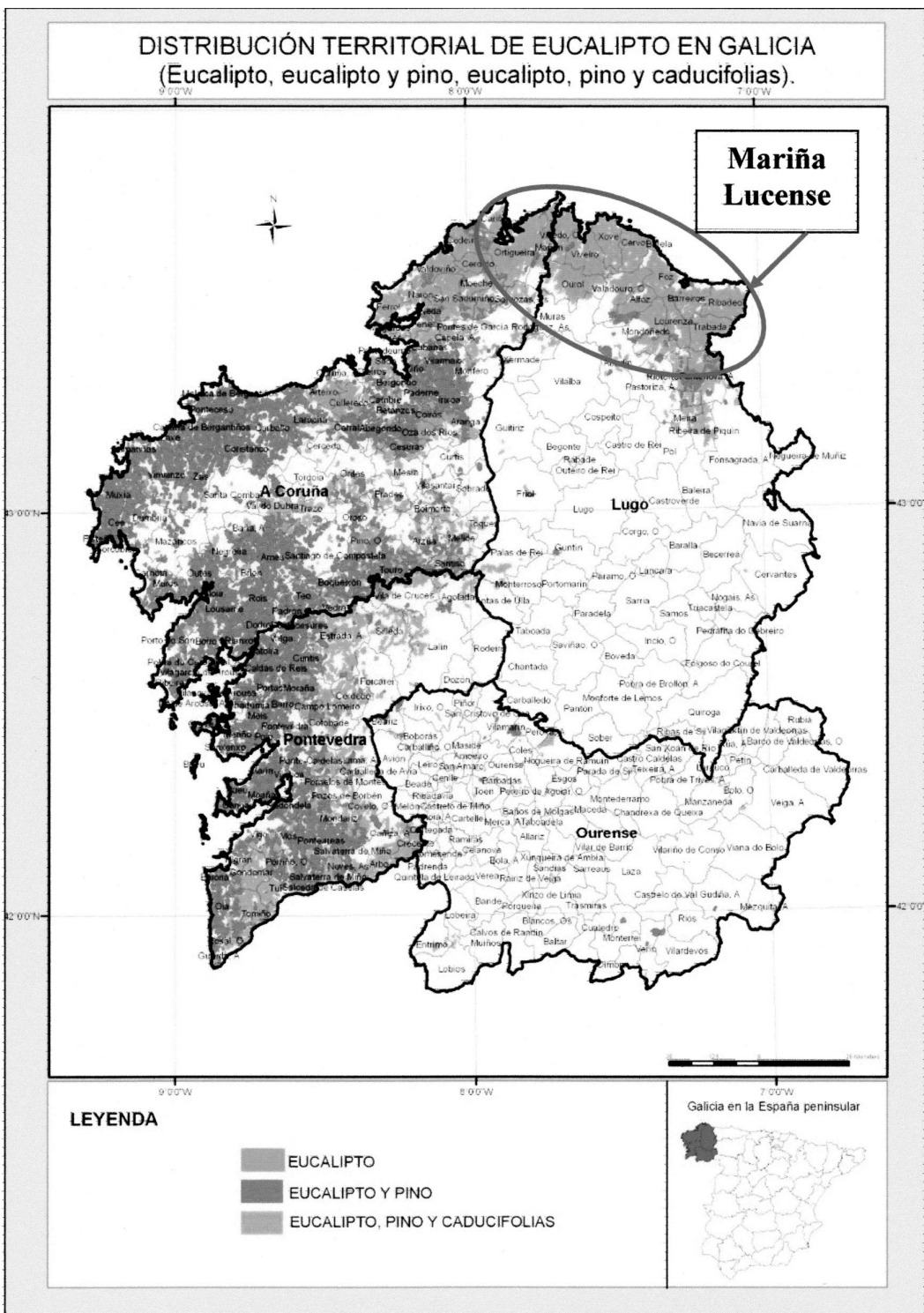

Fuente: elaboración propia a partir del Mapa de coberturas e usos do solo (SITGA, 2005). 
plares de pino. En estas zonas no se encuentran ejemplares tan viejos y grandes como en el norte de Lugo sino que son ejemplares que tienen la única finalidad de servir de materia prima para producir pasta de papel.

La significación del eucalipto en los montes de Galicia se incrementa al analizar las especies que forman montes de masas mixtas, donde esta especie tiene también una importante presencia. De hecho más de la mitad de los montes mixtos de Galicia están formados por eucaliptos y pinos y, aun tiene un valor mayor si también incluimos los montes que incluyen eucalipto, pino y caducifolias.

En cuanto a las diferentes opiniones que existen sobre esta especie, se puede considerar que posee una serie de aspectos positivos y otros negativos.

Dentro de los factores positivos destaca sobre los demás que el eucalipto, aunque sea una especie alóctona dadas sus características naturales en ciertas áreas de Galicia es la especie que mejor se adapta al medio y, puede alcanzar unos niveles de generación de beneficio muy elevados. Beneficios medioambientales como la fijación de $\mathrm{CO}_{2}$, beneficios naturales como la generación de áreas de superficie forestal arbolada o beneficios económicos como la generación de materia prima en un periodo de tiempo reducido.

En cuanto a las peculiaridades negativas de estas especies en este territorio, hay que hacer hincapié en que en gran medida se deben a la mala utilización y gestión que desde hace muchos años el hombre le dio a esta especie en Galicia. La falta de un plan de ordenación de los montes gallegos según las características naturales del territorio hasta hace pocos años y la no anticipación a las consecuencias que puede tener la realización de monocultivos (prevaleció el interés económico de los montes, producir la mayor cantidad de madera en el menor tiempo y espacio, frente a sus potencialidades sociales, culturales y medioambientales), provocó que el eucalipto domine hoy sobre otras especies. Ahora tenemos un gran número de hectáreas ocupadas por eucaliptos que se destina con exclusividad, a servir de materia prima para las industrias que producen pasta de papel. En relación con este último comentario, la razón de que el eucalipto gallego no se utilice dentro de la importante industria de la segunda transformación de la madera, se debe a que se trata de plantaciones con turnos de aprovechamiento y corte muy cortos. Si establecieran unos ritmos que permitiesen el mayor crecimiento de los eucaliptos y, por lo tanto, alcanzar mayores diámetros y, se respetasen unos turnos de corta más largos, la utilización de su madera para otros usos podría ser más rentable pues podría ser utilizada para otras actividades industriales más allá de la trituración. Sin embargo, los turnos de corta que se efectúan son cada 7 años y de un modo excepcional de 12 a 15 , por lo que su destino no puede ser otro que el de ser 
triturado para producir pasta de papel. Sería importante no permitir plantaciones rápidas de eucalipto, y por tanto permitir adquirir más porte a los diferentes ejemplares. $\mathrm{O}$ en el mejor de los casos promover plantaciones de eucalipto que oscilen desde las intensivas (destino trituración) y otras plantaciones con mayor separación entre ejemplares y turnos de corte más largos (madera segunda transformación).

En definitiva, el análisis realizado muestra como prácticamente todos los municipios gallegos cuenta con masas arbóreas. Éstas presentan variedad en especies arbóreas, el 55\% de las masas arbóreas son montes mixtos, las frondosas representan el $27 \%$ y las coníferas el $18 \%$. Al individualizar un poco dentro de las frondosas el $45 \%$ son eucaliptos, sucediendo algo similar dentro de las masas mixtas donde los montes de pino y eucalipto representan el 50\% del total de montes con masas arbóreas mixtas. Esta realidad forestal es consecuencia del papel que tuvo el monte a lo largo de la historia en Galicia, al estar al servicio de otras actividades y usos del suelo, y para la falta de ordenación forestal. De la mano de las políticas de repoblación, de la demanda de esta madera por parte de una gran empresa como es ENCE-Pontevedra, u otras actividades y la falta de cultura forestal de los propietarios, explica que la finalidad de los montes gallegos sea producir la mayor cantidad de pino y de eucalipto en el menor espacio y tiempo posible.

\section{LA PRESENCIA DE LA INDUSTRIA TRANSFORMADORA DE LA MADERA EN GALICIA}

Visto el potencial de materia prima que tiene el territorio gallego, se debería esperar que esta fuera aprovechada por empresas transformadoras que permitieran un aprovechamiento integral dentro de este territorio. Sus gentes han trabajado siempre la madera y saben de su importancia. Esto sin duda es un primer aspecto para justificar la relevancia de las empresas de transformación de madera presentes en Galicia. Sin embargo, los distintos hitos sociales, políticos y económicos han influido en la posible trayectoria negativa de estas actividades, tanto del recurso forestal examinado, como de las empresas que lo transforman. En este apartado se intenta mostrar cómo la relación existente es bastante parcial y, sobre todo, centrada en una parte muy pequeña de las potencialidades que tiene la transformación de la madera. Para comprobar esta circunstancia se examinan las características territoriales del universo de empresas que componen la industria transformadora de la madera gallega.

En la base de la explicación principal del cambio en la tipología de masas forestales tradicionales a la presencia de «especies nuevas», como el eucalipto, cabe destacar, entre todos los posibles acontecimientos que le influyeron, 
como se ha comentado, la instalación de una empresa pública productora de pasta de papel en Galicia (ENCE), en la ciudad de Pontevedra.

Aunque se inauguró a mediados del siglo xx, el proyecto de su instalación fue largo. Esto facilitó que desde mediados del siglo xix los procesos de repoblación de índole pública y privada se realizaran con especies arbóreas como el pino y después el eucalipto, siguiendo la única pretensión de producir madera apta para esta empresa. Realidades como la falta de ordenación y de conocimiento de los montes gallegos, el abandono de las tierras agrarias, el gran número de propietarios que vieron al monte como una «caja de ahorros» que había que rentabilizar del modo más rápido, entre otros factores, influyeron en que el monte gallego se especializase en producir una tipología de madera muy específica y con una utilidad industrial muy definida, la producción de pasta de papel.

Se buscaba que la materia prima estuviera cerca de la empresa transformadora. Esto generó que los bosques empezaran a cambiar la tipología de masas forestales y que las empresas que antes utilizaban las maderas autóctonas desaparecieran, cambiaran de lugar de suministro o, en menor medida se adaptaran a los nuevos recursos (Miramontes, 2010). La modificación del monte influyó en la especialización de los demás subsectores o actividades de la industria de transformación de la madera. Se comenzó a producir gran cantidad de madera de pino y de eucalipto, de árboles de rápido crecimiento, para una primera transformación, ya que no eran aptos para realizar una segunda.

Sin embargo no impidió que en Galicia actualmente estén representados todos los subsectores de la industria transformadora de la madera. En unos casos siguen aprovechando la materia prima y en otros la importan. De todos modos, la especialización de la industria de la madera hacia la primera transformación está más consolidada.

En cuanto a la caracterización y la localización de la industria transformadora de la madera en Galicia (figura 12), nos encontramos ante un sector que está compuesto por más de 2.500 empresas, presentes en prácticamente todo el territorio gallego. De hecho, en 9 de cada 10 municipios de Galicia hay alguna empresa relacionada con la transformación de la madera. Además existen una serie de áreas que presentan una mayor significación en cuanto al número de empresas transformadoras.

Se pueden diferenciar cuatro áreas principales en su distribución:

1. A lo largo de todo el Eje Urbano Atlántico, limitada por el trazado de la autopista del atlántico la AP-9 (desde Ferrol a Vigo, continuando hasta Portugal) abarca muchos municipios de las «Rías Baixas» (Ribeira, Vilagarcía de Arousa o Cangas). 
NÚMERO DE EMPRESAS TRANSFORMADORAS DE LA MADERA POR MUNICIPIO EN GALICIA

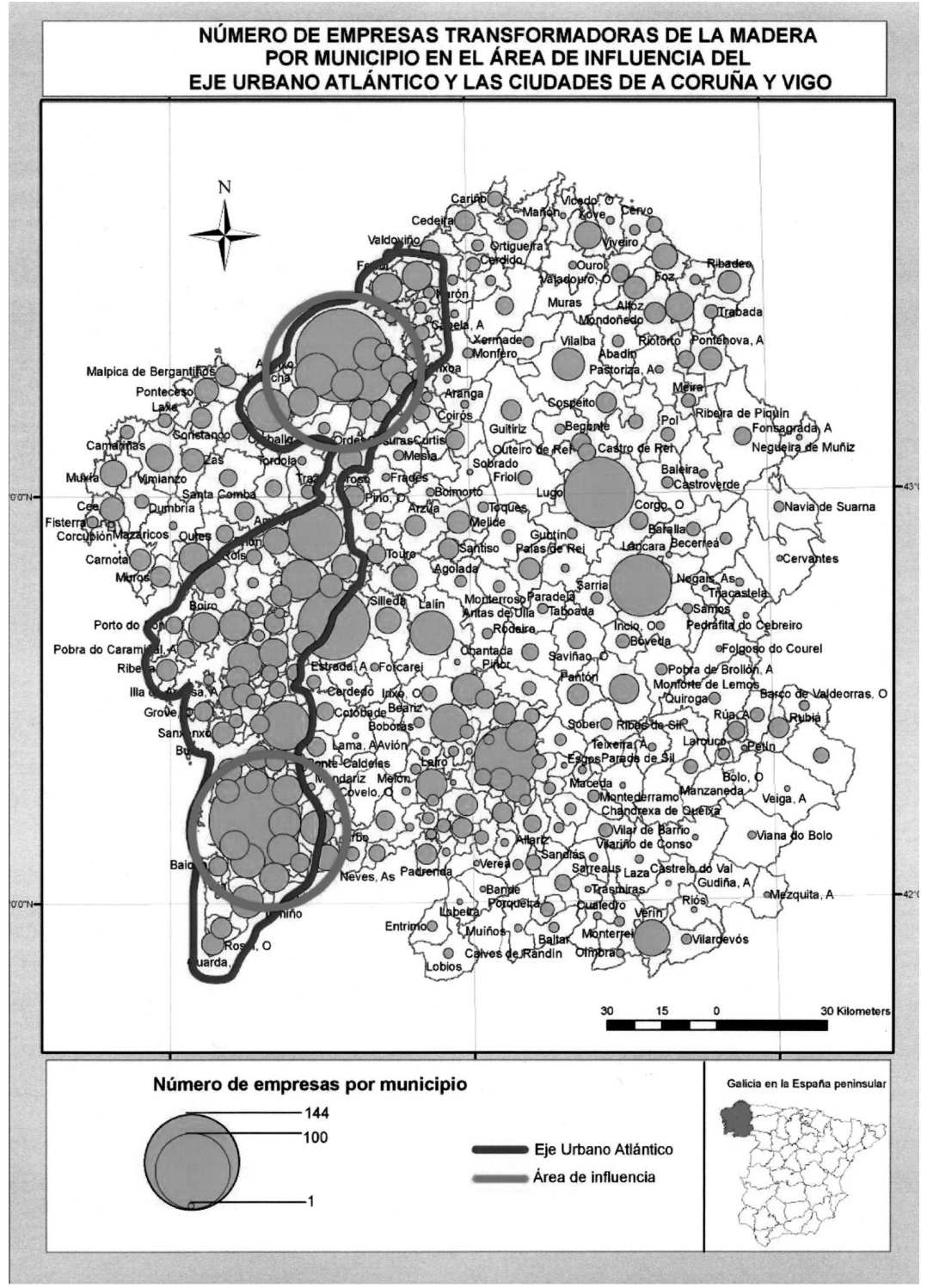

Fuente: elaboración propia a partir del Censo de Empresas de la Madera de Galicia (CIS-Madeira, 2003). 
2. Las áreas de influencia de las grandes ciudades gallegas (Coruña, Santiago de Compostela y Pontevedra) y de las capitales de provincia de Lugo y de Ourense.

3. Un considerable número de municipios que ejercen de cabecera comarcal como Ordes, Vilalba, Lalín o Monforte de Lemos.

4. Casos concretos de municipios que tienen un gran número de empresas que transforman madera como A Estrada o Sarria y áreas como la «Mariña Lucense» o el «Val Miñor».

$\mathrm{Al}$ analizar los valores generales (número de empresas, empleo y facturación) de las empresas transformadoras, distinguiendo entre primera y segunda transformación, observamos cómo el $73 \%$ de las empresas de la madera de Galicia se dedican a la segunda transformación. Este porcentaje define el peso del número de empresas, sin embargo las de primera transformación, con un peso numérico menor, son empresas de mayores dimensiones y con una importante facturación y empleo. Al analizar el número de empleados, se comprueba como la segunda transformación representa la mayoría, aunque con un 55\%, con lo que pierde significación con respecto al número de empresas. En gran medida porque dentro de la segunda transformación predominan los autónomos y las microempresas.

De todos modos las mayores diferencias entre la tipología de actividades se notan al observar la facturación de las empresas, donde la primera transformación es muy superior a las de la segunda. La primera transformación representa el $69 \%$ de la facturación de la industria transformadora de la madera frente al 31\% de la segunda. Las razones básicamente están en primer lugar en la presencia de la empresa FINSA, S.A. y a sus filiales (dedicada principalmente a la producción de tableros), y la planta de ENCE-Pontevedra, produc-

\section{CuAdro 1}

VALORES GENERALES DE LAS EMPRESAS TRANSFORMADORAS DE LA MADERA DE GALICIA

\begin{tabular}{lrrr}
\hline & $1^{\text {a }}$ Transformación & $2^{\text {a }}$ Transformación & \multicolumn{2}{c}{ Total } \\
\hline Empresas & $809(27 \%)$ & $2.177(73 \%)$ & 2.986 \\
Empleados & $6.924(45 \%)$ & $8.363(55 \%)$ & 15.287 \\
Facturación (euros) & $855.710 .988(69 \%)$ & $386.719 .072(31 \%)$ & 1.242 .430 .060 \\
\hline
\end{tabular}

Fuente: elaboración propia a partir del Censo de Empresas de la Madera de Galicia (CIS-Madeira, 2003) y otros. 
tora de pasta de papel. Estas dos representan cerca del 43\% de la facturación de las empresas de primera transformación de la madera de toda Galicia. El segundo factor explicativo se centra en que son empresas que mantienen una relación muy estrecha con el monte gallego, lo que les permite conseguir un rendimiento más elevado que ayuda a incrementar su facturación. El tercer factor es el reducido tamaño de muchas de las empresas de segunda transformación, que ofrece como resultado una suma de la facturación a escala de toda Galicia que no adquieren tanto protagonismo.

Esto está indicando que las empresas de primera transformación van a ser más relevantes para la economía gallega. Pero también está señalando el desequilibrio que existe dentro de la cadena de transformación de la madera de Galicia (cuadro 1).

Al cartografiar en un mismo mapa los valores de empleo y de facturación a escala municipal (figura 13), permite observar alguna característica más precisa de las empresas transformadoras de la madera en Galicia.

En primer lugar hay que tener en cuenta que los municipios que tienen mayor número de empleados en la industria transformadora de la madera no tienen porqué ser los que tienen mayor volumen de facturación. Esto se produce en gran medida porque en la actualidad muchas empresas de este sector en Galicia han evolucionado y se han adaptado a las nuevas tecnologías. Muchas producen en serie o han alterado parcialmente parte de los trabajos artesanales con la incorporación de maquinaria por lo que aumentan sus niveles de facturación, aunque redujeron el número de empleados.

En segundo lugar en una dimensión territorial se puede comprobar como dentro de la distribución de las empresas transformadoras de la madera se dan dos casos muy concretos: territorios que destacan por la actividad de una sola empresa, y otros que tienen una red formada por un número considerable de empresas que se dedican a esta actividad. Dentro de los municipios que tienen empresas grandes destacan zonas como la Mariña Lucense, Lalín, Santiago de Compostela o Padrón que sobresalen a escala gallega por el número de trabajadores y volumen de facturación, pero con pocas empresas.

A su vez, se detecta que dentro de los municipios que tienen mayores valores de empleo y facturación, la mayoría acogen empresas de primera transformación, aserraderos y productores de chapa y tableros, lo que nos comienza a confirmar la especialización de la industria transformadora de la madera de Galicia hacia la primera transformación, en gran medida como consecuencia de la madera que se producen en los montes gallegos y la influencia de dos empresas mencionadas, FINSA, S.A. y ENCE-Pontevedra. Por ello aunque los datos generales muestren un peso muy significativo en el número de empresas 
FIGURA 13

\section{RELACIÓN DE LA PRODUCTIVIDAD (EMPLEO-FACTURACIÓN) \\ DE LAS EMPRESAS TRANSFORMADORAS DE LA MADERA \\ POR MUNICIPIO EN GALICIA}

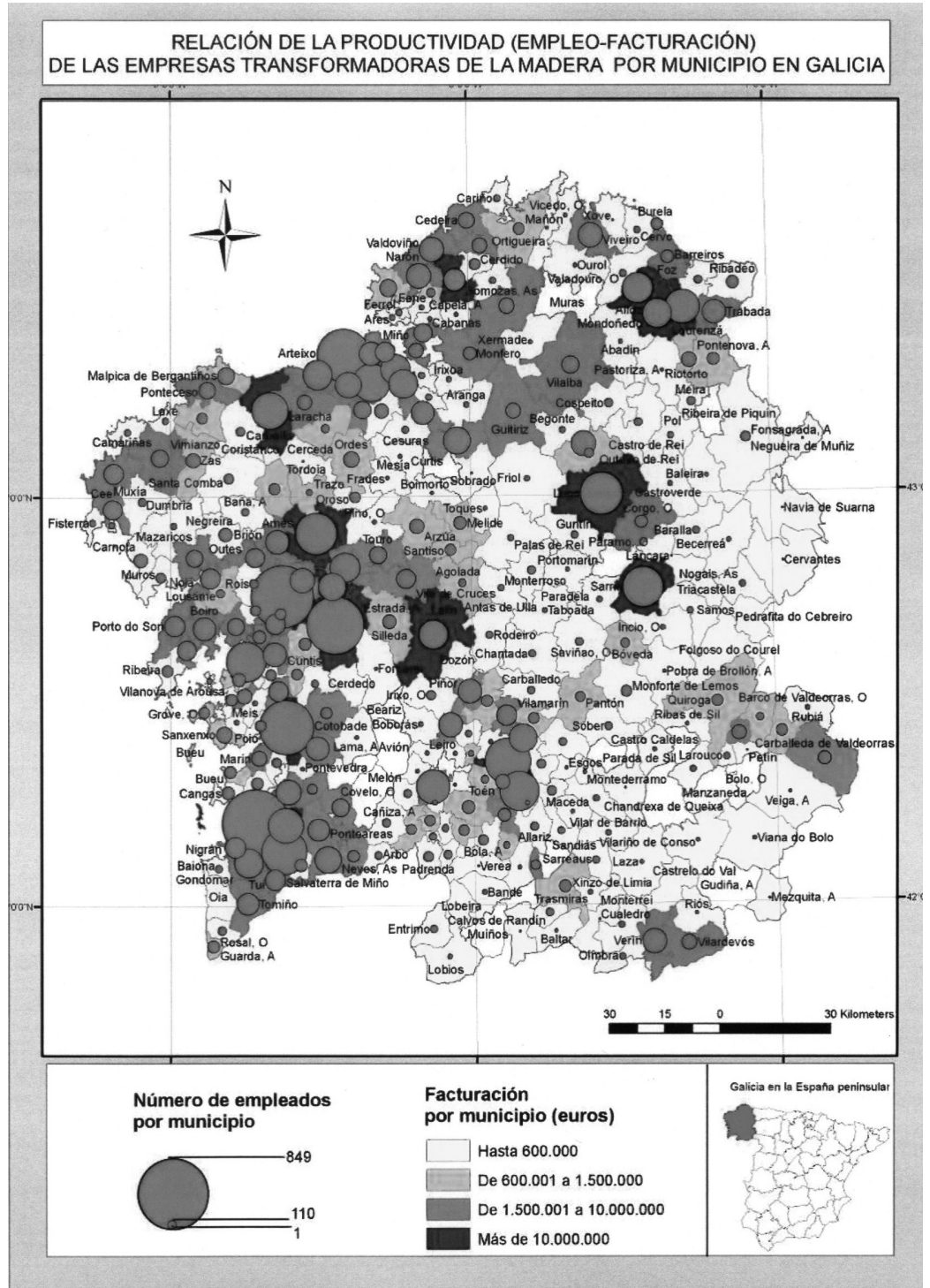

Fuente: elaboración propia a partir del Censo de Empresas de la Madera de Galicia (CIS-Madeira, 2003).

Estudios Geográficos, Vol. LXXIV, 274, pp. 153-191, enero-junio 2013

ISSN: 0014-1496, eISSN: 1988-8546, doi: 10.3989/estgeogr.201306 


\section{FIGURA 14}

\section{DISTRIBUCIÓN TERRITORIAL DE LAS EMPRESAS TRANSFORMADORAS DE LA MADERA POR MUNICIPIO Y DE LAS MASAS DE FRONDOSAS, CONÍFERAS Y MASAS MIXTAS}

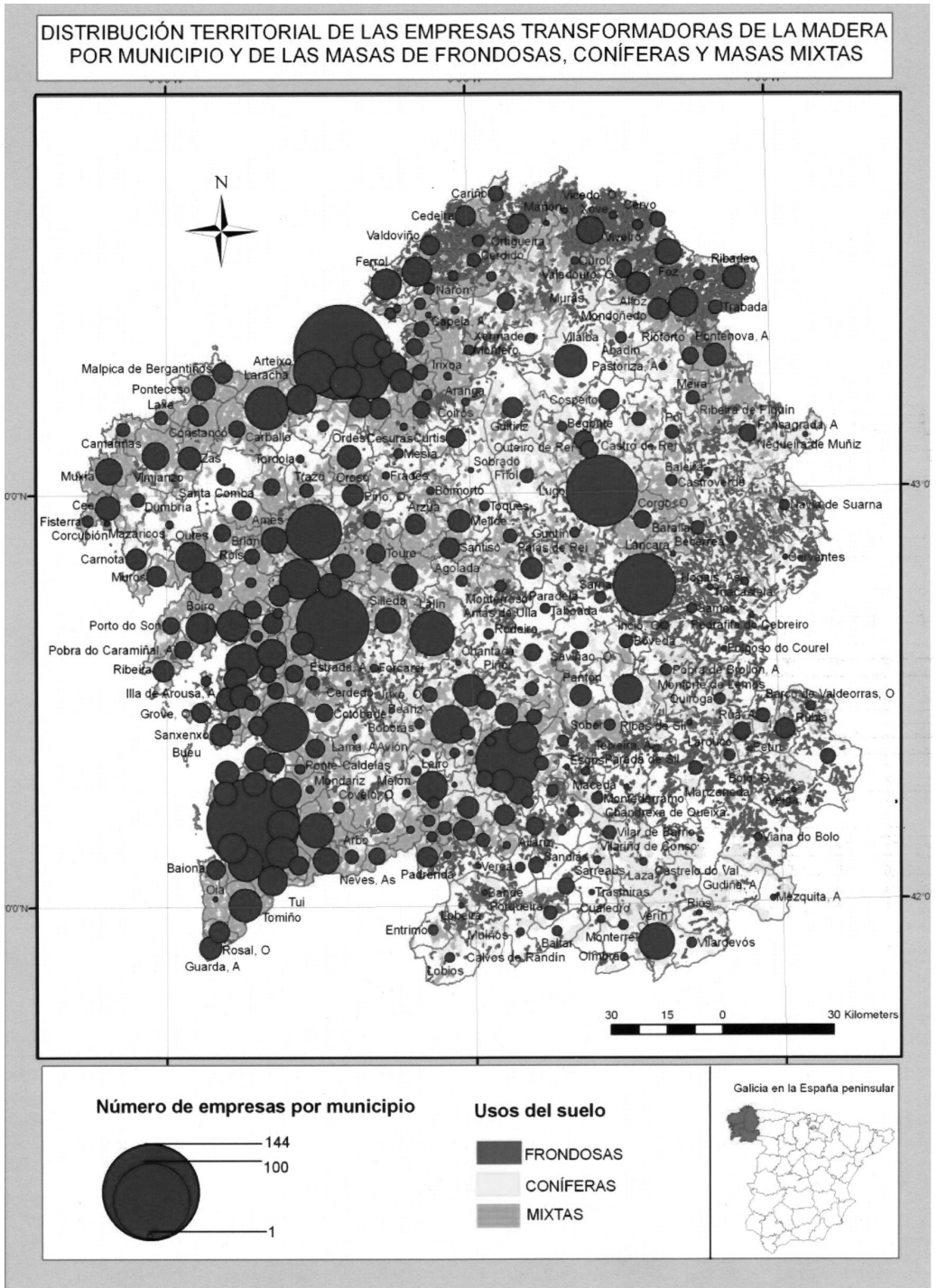

Fuente: elaboración propia a partir del «Censo de Empresas de la Madera de Galicia» (CIS-Madeira 2003) y el Mapa de coberturas e usos do solo de Galicia (SITGA, 2005). 
de segunda transformación, cuando se profundiza en otras variables y en la localización de las empresas se aprecia que realmente su peso es menor, y que en general son empresas que se dedican a solventar las necesidades locales. Aunque también hay excepciones a este planteamiento, así municipios como A Estrada o Sarria (en menor medida) destacan en la segunda transformación tanto por el número de empresas, empleados y el volumen de facturación de las empresas transformadoras de la madera que hay en estos municipios.

Para finalizar este apartado se ha realizado un análisis de la vinculación que existe entre la localización de las empresas transformadoras de la madera con los usos forestales de Galicia (figura 14). La conclusión más clara es que la mayoría de las empresas se encuentran en territorios donde hay un importante predominio del uso forestal. Pero tener en un mismo territorio amplias superficies forestales y un número considerable de empresas transformadoras de madera no significa que tengan relación, muchas de ellas tienen necesidades de importar. Esta realidad es bastante contradictoria cuando se comprueba como en países como Austria, Suiza o Francia, muchos empresarios afirman que se abastecen de la madera de los montes que se encuentran en un radio de 50 kilómetros de distancia de sus empresas (Miramontes, 2010).

$\mathrm{Al}$ observar las masas forestales por tipos, y relacionarlas con la localización de las empresas se comprueba como realmente la mayoría de empresas transformadoras de la madera se encuentran próximas a áreas arbóreas mixtas. Esto indica que estas empresas utilizan mayoritariamente el pino y el eucalipto para su proceso productivo, y además esto se relaciona con las empresas de la primera transformación. Frente a esto en las áreas en las que predominan las frondosas el número de empresas es menor, exceptuando el norte de la provincia de Lugo en donde se encuentra uno de los eucaliptales más importantes de la Europa Atlántica. Las proximidades de las empresas transformadoras de madera más importantes como FINSA S.A. en Santiago de Compostela o ENCE-Pontevedra el predominio de masas mixtas de pino y eucalipto es muy importante, lo que demuestra como la proximidad de la materia prima en algunas actividades continua siendo un factor de localización.

En cuanto a la escasa localización de empresas transformadoras en las áreas de predominio de frondosas, especialmente en zonas de castaños y robles, en el interior de las provincias de Lugo y Ourense, se explica porque su ubicación se corresponde con municipios montañosos, muchos de ellos en procesos de abandono, donde las masas forestales no reciben cuidados del hombre. Se trata de montes en los que los árboles no son podados, ni atendidos para poderse destinar a la industria transformadora de la madera, por lo 
que aunque sus maderas son demandadas por empresas de segunda transformación como las carpinterías y las fábricas de muebles, estás se ven obligadas a importarlas.

En Galicia el problema está en que no se produce una importante relación productiva entre presencia de materia prima y empresas transformadoras. Hay muchas actividades relacionadas con la transformación de la madera que necesitan traer de fuera su materia prima, otras no o en menor medida, entre ellas la empresa de pasta de papel de Pontevedra, beneficiada en la reordenación forestal de Galicia, y precisamente de la presencia de determinadas masas forestales. Se comprueba por tanto, la infrautilización que existe en Galicia de la potencialidad forestal, puesto que hay un predominio de recursos forestales de crecimiento rápido, y cuyos usos generan escaso valor, y falta madera con más años de tratamiento y con especies que permitiera a las empresas como las del sector del muebles ofrecer un mayor valor añadido a la materia prima presente en este territorio.

Por todo esto, se aprecia que la industria de la madera gallega cada vez está más especializada en actividades de primera transformación de la madera, tanto por la influencia de ciertas grandes empresas, como por la política de ordenación de los montes para producir en exclusividad la madera de rápido crecimiento apta para estas actividades. Además las empresas de la primera transformación consumen la mayoría de la madera que se transforma en Galicia, más del 80\% (Miramontes, 2010). Por lo que, se corrobora de nuevo otro de los desequilibrios dentro de la cadena de la madera de Galicia. La primera transformación consume mucha más madera gallega que la segunda y, además una vez que recibe una primera transformación no es consumida por las empresas de la segunda transformación de Galicia. Se exporta mucha madera sin transformar completamente. No pudiendo el saber hacer de muchas empresas de segunda transformación especializadas aprovechar materia prima local.

La cadena de la madera en Galicia se encuentra en un claro desequilibrio producción-consumo. Galicia también importa madera, sin transformar y con una primera transformación, que después comercializa para abastecer a la demanda de las empresas gallegas. Aunque lo más significativo es que dentro de las especies de la madera que importa la mayoría es pino, a pesar de ser la que más se produce en el monte gallego (recordemos que con unas características muy específicas para serrar y triturar y producir pasta de papel) y otras especies arbóreas como el roble o el castaño, que durante muchos siglos fueron las especies predominantes de los montes gallegos. Las repoblaciones forestales potenciaron especies de rápido crecimiento aptas para las empresas de pri- 
mera transformación, llegando en algunos espacios a desplazar especies que usaban las empresas tradicionales de transformación de la madera.

\section{CONCLUSIONES}

Los recursos forestales tanto en el pasado como en el presente continúan siendo requeridos por empresas que buscan una proximidad en cuanto a su localización, pero a diferencia de lo que ocurría antes, hoy en día también es posible encontrar empresas donde no persiste esa relación de proximidad. Existen establecimientos fabriles que pueden traer la materia prima de lugares distantes para fabricar sus productos acabados, ya que los avances en los medios de transporte y en la logística han sido muy relevantes.

En el caso de Galicia el análisis del recurso actual maderero y de las empresas que lo transforman permite comprobar la existencia de esa doble posibilidad de relación. Las circunstancias socioeconómicas llevaron a este territorio a un cambio en la composición de sus masas forestales tradicionales. Si en el pasado dominaban en sus bosques los castaños, robles o árboles de ribera; en el presente lo hacen especies de rápido crecimiento como el pino y el eucalipto. Esto ha provocado consecuencias. En primer lugar la presencia masiva de los bosques de pino y eucalipto, algo que a su vez favorece la presencia de empresas de primera transformación (preparación de tableros, pasta de papel, aserraderos,..). Son empresas que precisan mucha materia prima y disponer de ella en su proximidad. Por tanto, el factor de proximidad al recurso natural, sigue siendo un elemento explicativo de localización empresarial.

En segundo lugar, al cambiar las especies predominantes también se ha modificado el tipo de empresas de transformación. En Galicia el trabajo sobre la madera, era una actividad tradicional, con parroquias especializadas en fabricar utensilios de madera (Carmona y Nadal, 2005; Prada, 1991; Balboa, 1990; Nadal y Carreras, 1990; Madoz, 1845), pero a medida que se produce el vaciado de muchas áreas rurales esta actividad va desapareciendo. Es entonces cuando las masas forestales se adaptan también a otras necesidades. Sin embargo, en algunos espacios la tradición del trabajo sobre la madera no se pierde, y esto favorece que el "saber hacer» consiga mantener empresas especializadas en la fabricación del mueble o que las carpinterías abastezcan a las necesidades de la población en los distintos municipios. En la mayoría de estos casos la relación de la materia prima con sus entornos se ha roto, puesto que la madera que precisan este tipo de actividades demanda una madera de 
mejor calidad que la que se utiliza bien para la trituración de pasta de papel o para tableros.

Se puede por tanto indicar que en Galicia se ha dado un proceso de adaptación de sus recursos forestales a la tipología empresarial que en un determinado momento se implantó en Galicia. Esta especialización de los recursos forestales influye no sólo en el tipo de especies sino en las características de su corte. Tanto el pino como el eucalipto son especies que podrían asociarse a actividades de segunda transformación, pero para ello es necesario ejemplares con más calidad, procedentes de turnos de corta más largos. Esto permitiría obtener nuevas utilidades de estas maderas, más allá de la producción de pasta de papel o de tableros de baja calidad.

Sería también necesario potenciar en el monte gallego la presencia de otra tipología de madera según las características naturales del territorio, y que además demandan las empresas de segunda transformación. Esto permitiría frenar el monocultivo de coníferas y de eucaliptos o por lo menos realizar otro tipo de plantaciones menos intensivas.

Así se comprueba que la cadena de la madera no se completa en Galicia. Se supone que el monte debe producir madera, los aserraderos talan esos árboles y realizan una primera transformación, que esa madera pase a la plantas productoras de tableros o productos de madera, para que después las empresas de la segunda transformación, carpinterías y fábricas de muebles, transformen definitivamente esa madera y fabriquen un producto final que adquiere el mayor valor añadido sobre la madera que se obtuvo del monte. Sin embargo, como consecuencia directa de las políticas forestales que se iniciaron en Galicia desde mediados del siglo XIX, se limitan las potencialidades productivas de madera de los montes gallegos y se condiciona a la especialización de los aserraderos a trabajar con ejemplares de pino muy jóvenes, a que se triture la madera para convertirse en pasta de papel, o que se prepare la madera en tableros, pero se rompe la cadena de la madera porque los productos de esta primera transformación no reciben la segunda en Galicia, la mayoría se exporta. Se rompe la cadena pero no impide que Galicia sea uno de los territorios españoles donde no sólo tienen significación los recursos forestales de sus montes, sino también una importante industria transformadora.

Fecha de recepción: 04/06/2012

Fecha de aceptación: 04/03/2013 
BiBLIOGRAFÍA

Albertos Puebla, J. M. et al. (2004): "Desarrollo territorial y procesos de innovación socioeconómica en sistemas productivos locales", en J. L. Alonso Santos, L. J. Aparicio Santos y J. L. Sánchez Hernández (eds.): Recursos territoriales y geografía de la innovación industrial en España. Salamanca, Ediciones Universidad de Salamanca, pp. 15-60.

Alonso, J. L., Aparicio, L. J. y Sánchez, J. L. (eds.) (2004): Recursos territoriales y geografía de la innovación industrial en España. Salamanca, Ediciones Universidad de Salamanca, $352 \mathrm{pp}$.

Alonso, M. ${ }^{a}$ P. y Lois, R. C. (1997): "Proceso de industrialización y organización del espacio en un territorio periférico: Galicia". Boletín de la Asociación de Geógrafos Españoles. Transformaciones económicas y reorganización espacial, 24, pp. 91-106.

Artiaga Rego, A. (1991): A desamortización na provincia de Pontevedra (1855-1900). Pontevedra, Servicio de Publicaciones Diputación Provincial de Pontevedra, 295 pp. Asociación Monte-Industria et al. (2007-2008): Industria Forestal en Galicia 20072008. Santiago de Compostela, Asociación Monte-Industria, FEARMAGA y el Cluster da Madeira de Galicia, 15 pp.

Balboa López, X. (1990): O monte en Galicia. Vigo, Editorial Xerais, 359 pp.

Caravaca Barroso, I., González, G., Méndez, R. y Silva, R. (2002): Innovación y territorio: análisis comparado de sistemas productivos locales en Andalucía. Sevilla, Junta de Andalucía, Consejería de Economía y Hacienda, 392 pp.

Carmona, X. y Nadal, J. (2005): El empeño industrial de Galicia, 250 años de historia, 1750-2000. A Coruña, Fundación Pedro Barrié de la Maza, 443 pp.

CIS-Madeira (2003): Censo de empresas de la madera en Galicia. Santiago de Compostela, Consellería de Industria y Comercio, Xunta de Galicia, CD-ROOM.

Cruz Aguilar, E. (1994): La destrucción de los montes (claves histórico-jurídicas). Madrid, Universidad Complutense de Madrid, 287 pp.

FAO (Organización de las Naciones Unidas para la Agricultura y la Alimentación) (2012): El estado de los bosques del mundo 2012. Roma, Departamento Forestal, 64 pp.

FAO (Organización de las Naciones Unidas para la Agricultura y la Alimentación) (2010a): Evaluación de los Recursos Forestales Mundiales 2010. Roma, Departamento Forestal, 378 pp.

FAO (Organización de las Naciones Unidas para la agricultura y la alimentación) (2010b): Situación de los Bosques del Mundo 2009. Roma, Departamento Forestal, $158 \mathrm{pp}$.

Fernández, J. (1984): "Situación actual y perspectivas de los castañares tradicionales gallegos", en Xunta de Galicia (ed.): Congreso Internacional sobre el castaño. 1 a 5 de octubre, Lourizán. Galicia, Departamento de Investigación Forestal, pp. 105119.

Ferreira, E. (1988): Galicia en el comercio marítimo medieval. A Coruña, Fundación Pedro Barrié de la Maza, 903 pp. 
Fischer R., Lorens M., Köhl M., Mues V., Granke O., Iost S. Van Dobben H., Reinds GJ. y de Vries W. (2010): The Condition of Forest in Europe. Executive Report. IPC Forest and European Commission, Hambur and Brussels, 21 pp.

Galiforest (2010): Monográfico Forestal Internacional para el Sur de Europa. Silleda (Pontevedra), Fundación Semana Verde de Galicia, Xunta de Galicia.

Guitián Rivera, L. (1995): "Origen y evolución de la cubierta forestal de Galicia”. Tesis doctoral. Universidad de Santiago de Compostela. Santiago de Compostela, 474 pp.

INE (Instituto Nacional de Estadística) (2010): INEbase, http://www.ine.es.

Madoz, P. (1845): Diccionario geográfico-estadístico. Galicia. Madrid, Imprenta del Diccionario Geográfico-Estadístico-Histórico de D. Pascual Madoz.

Méndez Gutiérrez del Valle, R. (1997): Geografía económica. La lógica espacial del capitalismo global. Barcelona, Editorial Ariel, 384 pp.

Méndez Gutiérrez del Valle, R. (1998): "Innovación tecnológica y reorganización del espacio industrial: una propuesta metodológica”. EURE. Revista Latinoamericana de Estudios Urbanos Regionales, 73, pp. 31-54.

Méndez Gutiérrez del Valle, R. (2000): "Procesos de innovación en el territorio: los medios innovadores", en J. L. Alonso, J. Alonso Santos y J. L. Sánchez Hernández (eds.): Innovación, pequeña empresa y desarrollo local en España. Madrid. Editorial Civitas, pp. 23-59.

Méndez Gutiérrez del Valle, R. (1994): "Sistemas productivos locales y políticas de desarrollo rural". Revista de Estudios Regionales, 39, pp. 93-112.

Méndez Gutiérrez del Valle, R. (2001): "Sistemas productivos locales y políticas de desarrollo rural". Revista de Estudios Regionales, 39, pp. 93-112.

Méndez, R. y Alonso, J. L. (coords.) (2000): Innovación, pequeña empresa y desarrollo local en España. Madrid. Editorial Civitas, 323 pp.

Méndez, R. y Alonso, J. L. (eds.) (2002): Sistemas Locales de Empresas y redes de innovación en Castilla - La Mancha y Castilla y León. Salamanca, Universidad de Salamanca, 295 pp.

Méndez, R. y Caravaca, I. (1996): Organización industrial y territorio. Madrid, Síntesis, $365 \mathrm{pp}$.

Méndez, R. et al. (2004): "La industria de la madera y el mueble en Castilla-La Mancha: entre la tradición y la innovación" en J. L. Alonso Santos, L. J. Aparicio Santos y J. L. Sánchez Hernández (eds.): Recursos territoriales y geografía de la innovación industrial en España. Salamanca, Ediciones Universidad de Salamanca, 2004, pp. 189-222.

Ministerio de Medio Ambiente (2002): Plan Forestal de España. Madrid, Dirección General de la Naturaleza, 134 pp.

Ministerio de Medio Ambiente. Anuario de Estadística Forestal. Madrid. Dirección General para la Biodiversidad. Varios años.

Ministerio de Medio Ambiente y Medio Rural y Marino (2011): Los incendios forestales en España año 2010. Madrid, Área de Defensa Contra Incendios Forestales, $85 \mathrm{pp}$. 
Miramontes Carballada, Á. (2010): La industria de la madera en Galicia. La significación del subsector del mueble. Santiago de Compostela, Servicio de Publicaciones de la Universida de de Santiago de Compostela, 695 pp.

Montiel Molina, C. (2003): "El patrimonio forestal mediterráneo: componentes y valoración". Bois et Forèts des tropiques, 276, pp. 73-83.

Nadal, J. y Carreras, A. (1990): Pautas regionales de la industrialización española (siglo: XIX-XX). Barcelona, Editorial Ariel, 437 pp.

Ortuño Pérez, S. F. y Zamora, R. (2001): "Las áreas de montaña y los modelos de desarrollo rural". Revista española de estudios agrosociales y pesqueros, 191, pp. 41-60.

Piussi P. y Farrell E. P. (2000): "Interactions between society and forest ecosystems: challenges for the near future". Forest Ecology and Management, 132, pp. 21-28.

Prada Blanco, A. (1991): Montes e industria. O circuito da madeira en Galicia. A Coruña, Fundación Caixa Galicia, 302 pp.

Precedo, A. y Villarino, M. (1991): "Desindustrialización y reestructuración de los Sistemas Urbanos Regionales en el norte de España: análisis comparado de las ciudades de Galicia, Asturias y Cantabria". Treballs de la Societat Catalana de Geografía. Barcelona, 31 pp.

Rico Boquete, E. (1993): “A riqueza forestal de Galicia no século XX: producción e explotación". Tesis doctoral. Universidade de Santiago de Compostela.

Rico Boquete, E. (1997): La Creación de Celulosas de Pontevedra y su influencia en el sector forestal de la provincia. Madrid, Fundación Empresa Pública, Programa de Historia Económica, 159 pp.

Rico Boquete, E. (1995): "Política Forestal e repoboacións en Galicia (1941-1971)". Santiago de Compostela, Servicio de Publicacións e Intercambio Científico. Universidade de Santiago de Compostela, 167, 202 pp.

Rodríguez Galdo, M. X. (1989): "La agricultura gallega en el siglo XVIII", en Ministerio de Agricultura, Pesca y Alimentación (ed.): Estructuras agrarias y reformismo ilustrado en la España del siglo XVIII. Madrid, Ministerio de Agricultura, Pesca y Alimentación, pp. 63-78.

Salom Carrasco, J. (2003): "Innovación y actores locales en los nuevos espacios económicos: un estado de la cuestión”. Boletín de la Asociación de Geógrafos Españoles, 36, pp. 7-30.

Salom, J. y Albertos, J. M. (2009): Redes socioinstitucionales, estrategias de innovación y desarrollo territorial en España. Valencia, Colección Desarrollo Territorial, Serie Estudios y Documentos, 6. Publicaciones de la Universitat de Valencia, 202 pp.

SITGA (Sistema de Información Territorial de Galicia) (2005): Mapa de coberturas e usos do solo de Galicia. Santiago de Compostela, Consellería do Medio Rural, Xunta de Galicia, Formato CD.

Urteaga, L. (1987): La Tierra esquilmada. Las ideas sobre la conservación de la naturaleza en la cultura española del siglo XVIII. Barcelona - Madrid, Serbal - CSIC, 221 pp.

Valdés, C. M. y Gil, L. (2001): La transformación histórica del paisaje forestal en Galicia. Madrid. Ministerio de Medio Ambiente, 159 pp. 


\begin{abstract}
RESUMEN
En los estudios sobre la conformación de sistemas productivos empresariales se olvida cada vez más, la significación que puede tener para su conformación y éxito la presencia de materia prima cercana. Es cierto, que los avances en los medios de transporte, entre otros condicionantes, facilitan que se aleje el lugar de transformación del de suministro de la materia prima. Sin embargo, en muchas actividades la presencia fabril está todavía muy condicionada por la localización y características de los materiales con los que fabricar. Un buen ejemplo es la industria de la madera. En concreto este artículo se centra en mostrar la relación, significación y potencialidad económica de la materia prima forestal y la industria de transformación de la madera en Galicia.
\end{abstract}

Palabras Clave: monte; industria de la madera; Galicia.

\begin{abstract}
In studies on the creation of corporate production systems, the significance that the proximity of raw material can have on its success and creation is increasingly overlooked. It is true that advances in transportation, among other conditions, make it easy to move the processing plant farther away from where the raw material is supplied. However, in many activities the manufacturing location is still conditioned by the location and characteristics of the materials used in production. A good example is the timber industry. This article specifically focuses on showing the relationship, significance and economic potential of forest raw materials and the wood processing industry in Galicia.
\end{abstract}

KEY WORDS: forestland; wood industry; Galicia.

\title{
RÉSUMÉ
}

Les études sur la formation des systèmes productifs commerciaux oublient de plus en plus l'importance que peut avoir pour leur formation et leur succès la présence proche de matières premières. Il est vrai que les progrès des moyens de transport, parmi d'autres autres conditions, facilitent l'éloignement du lieu de transformation de celui d'approvisionnement de la matière première. Cependant, en de nombreuses activités, la présence d'usines est encore fortement influencée par l'emplacement et les caractéristiques des matériaux à employer. Un bon exemple est celui de l'industrie du bois. Cet article prétend, en particulier, montrer la relation, la signification et le potentiel économique des matières premières forestières et de l'industrie de transformation du bois en Galice.

MOTS CLÉS: monts; industrie du bois; Galice. 